\title{
Epigenetics and Autoimmune Diseases
}

\author{
Paula Quintero-Ronderos and Gladis Montoya-Ortiz \\ Center for Autoimmune Diseases Research (CREA), School of Medicine and Health Sciences, Universidad del Rosario, \\ Carrera 24 no. 63C-69 Bogotá, Colombia
}

Correspondence should be addressed to Gladis Montoya-Ortiz, gladis.montoya@gmail.com

Received 11 October 2011; Revised 6 December 2011; Accepted 14 December 2011

Academic Editor: Juan-Manuel Anaya

Copyright ( $) 2012$ P. Quintero-Ronderos and G. Montoya-Ortiz. This is an open access article distributed under the Creative Commons Attribution License, which permits unrestricted use, distribution, and reproduction in any medium, provided the original work is properly cited.

\begin{abstract}
Epigenetics is defined as the study of all inheritable and potentially reversible changes in genome function that do not alter the nucleotide sequence within the DNA. Epigenetic mechanisms such as DNA methylation, histone modification, nucleosome positioning, and microRNAs (miRNAs) are essential to carry out key functions in the regulation of gene expression. Therefore, the epigenetic mechanisms are a window to understanding the possible mechanisms involved in the pathogenesis of complex diseases such as autoimmune diseases. It is noteworthy that autoimmune diseases do not have the same epidemiology, pathology, or symptoms but do have a common origin that can be explained by the sharing of immunogenetic mechanisms. Currently, epigenetic research is looking for disruption in one or more epigenetic mechanisms to provide new insights into autoimmune diseases. The identification of cell-specific targets of epigenetic deregulation will serve us as clinical markers for diagnosis, disease progression, and therapy approaches.
\end{abstract}

\section{Introduction}

Epigenetics was defined by Conrad Waddington in the early 1940 s as the branch of biology that studies the causal interactions between genes and their products which bring the phenotype into being [1]. Currently, epigenetics is defined as the study of changes in gene function that are inheritable and that do not entail a change in DNA sequence [2]. As has been mentioned before, all these mechanisms are inheritable thus the epigenetic markers have the ability to persist during development and potentially be transmitted from offspring to offspring. These mechanisms play an essential role in regulation of gene and miRNA expression, DNAprotein interactions, cell differentiation, embryogenesis, Xchromosome inactivation, and genomic imprinting [3].

One of the main functions of epigenetics is gene regulation. Gene regulation plays an important role in determining individual gene function and activity, the sets of genes which are functional in each specific cell type, cell type development and differentiation, and metabolic plasticity of the cell that allows it to adapt itself to environmental changes. However, it is important to note that epigenetics is not the only determinant of gene function. There are intrinsic components that are stable over time and are the same in each cell type. These intrinsic components, which include polymorphism and mutations, are among the mechanisms that affect gene expression. Also, the environment (virus, hormones, nutrition, and chemicals) influences epigenetics and thus, the intrinsic component altering gene function [4].

The interaction between environment and epigenetics is only one of the mechanisms by which a large range of different phenotypes arise from the same genotype such as in the case of monozygotic twins [5, 6]. Monozygotic twins have an identical DNA sequence, but studies have found some phenotypic differences that may be consequences of different exposures to environmental stressors. These exposures produce alterations in the DNA methylation pattern and histone modification. This condition may be one of the causes of the differences found in the concordance rate of autoimmune diseases between monozygotic twins (Table 1) [7-22].

Another example of how epigenetics interact with the environment is in the study of pregnant Agouti rodents. In this study, researchers fed pregnant Agouti rodents with food rich in methyl donors such as folate, methionine, 


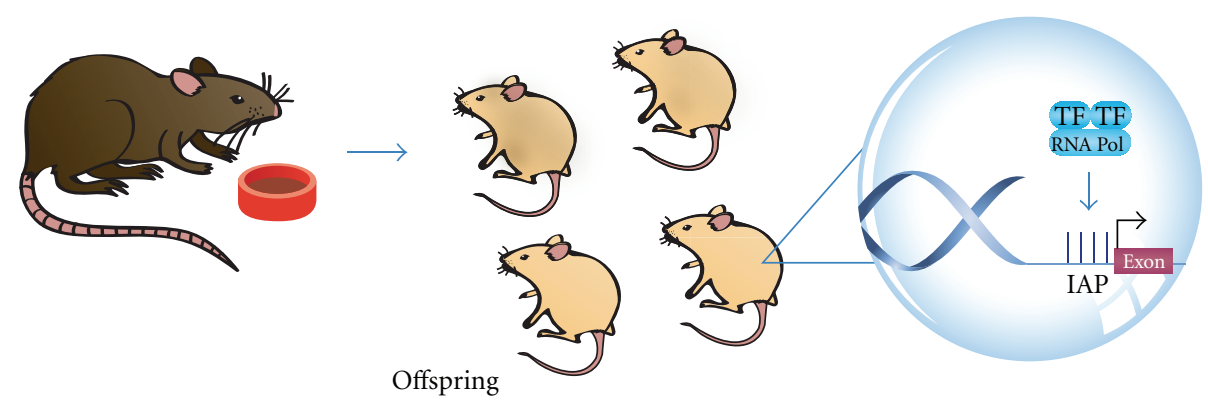

(a)

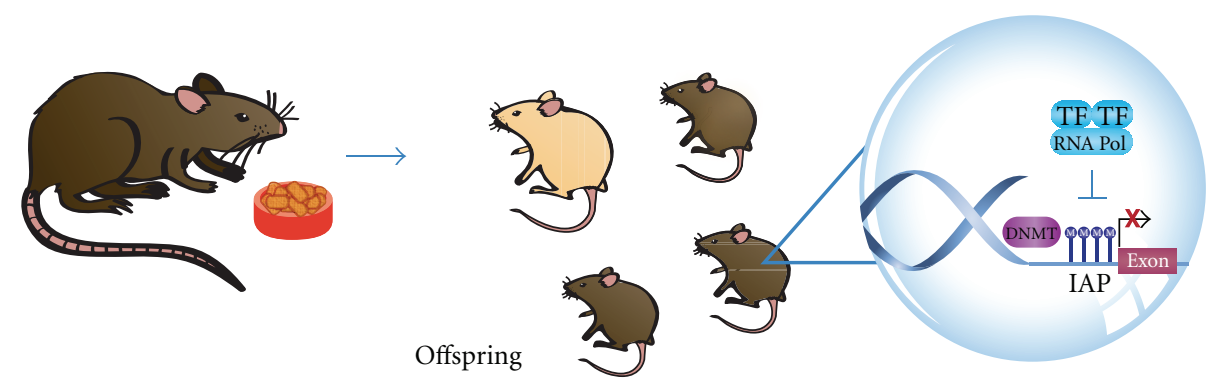

(b)

FIGURE 1: Epigenetic-environmental interaction. Offspring of pregnant Agouti rodents fed with food rich in methyl donors had a different color of coat (brown, (b)) due to an increased DNA methylation status in the viable yellow allele ( $A^{\text {vy }}$ allele), in comparison to offspring of pregnant rodents fed a normal diet (yellow or mottle, (a)). Intracisternal A Particle (IAP), Transcription Factor (TF), RNA Polymerase (RNA Pol), Methylated Cytosine (M).

TABLE 1: Concordance rate of autoimmune diseases between monozygotic twins.

\begin{tabular}{lcc}
\hline Autoimmune disease & Concordance rate & References \\
\hline Systemic lupus erythematosus & $11-25 \%$ & {$[7]$} \\
& & {$[8]$} \\
\hline Type I diabetes mellitus & $13-48 \%$ & {$[10]$} \\
& & {$[11]$} \\
& & {$[12]$} \\
& & {$[13]$} \\
Rheumatoid arthritis & $12-22 \%$ & {$[14]$} \\
& & {$[15]$} \\
Grave's disease & $22.2 \%$ & {$[16]$} \\
\hline & & {$[17]$} \\
Multiple sclerosis & $9-31 \%$ & {$[18]$} \\
& & {$[19]$} \\
\hline Celiac disease & $75-83 \%$ & {$[20]$} \\
\hline
\end{tabular}

and choline. They found that, in comparison to offspring of pregnant rodents fed a normal diet (yellow or mottle,
Figure 1(a)), the offspring of these rodents had a different color of coat (brown, Figure 1(b)) due to an increased DNA methylation status in the viable yellow allele $\left(A^{\text {vy }}\right.$ allele). These authors demonstrated that the percentage of phenotypes with a darker brown coat rises as increasing levels of methyl supplement are added to the diet. The lack of a methyl supplement has important implications because it indicates a pattern of future obesity and insulin resistance. In other words, mice with yellow or mottle coats have altered metabolism and obesity. It also results in increased cancer susceptibility, adult diabetes, and twice the mortality seen in normal mice [58].

Other researchers showed that Dutch who were exposed prenatally to famine during the Dutch Famine of 1944 in World War II had less DNA methylation of the imprinted Insulin-like growth factor 2 (IGF-2) gene 6 decades later compared to their unexposed, same-sex siblings. Because of the lack of nutrients that these individuals suffered during prenatal life, there was a deficiency of methyl donors such as the amino acid methionine that causes the hypomethylation of the differentially methylated region (DMR) in the maternally imprinted IGF-2 gene in comparison to same sex siblings who were not exposed. Even though the IGF-2 gene plays a key role in human growth and development, there was no evidence with respect to the relationship between hypomethylation of IGF-2 and birth weight. Thus, 


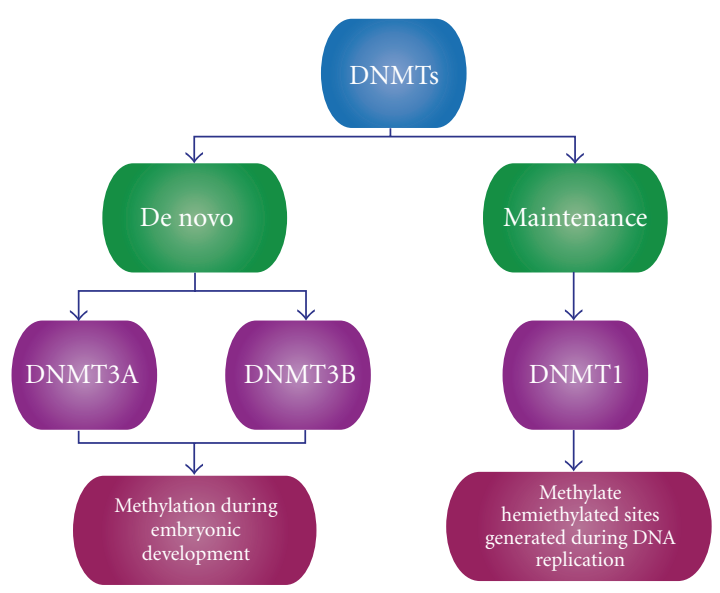

FIGURE 2: Classification of DNMTs. DNMTs can be classified into de novo and maintenance. De novo DNMTs are involved in methylation during embryonic development, and maintenance DNMTs are involved in methylation during DNA replication.

this finding supports the hypothesis that early mammalian development is important for establishing and maintaining epigenetic markers $[59,60]$.

Many studies had been done of the cohort from the Dutch Winter of Famine in World War II. One of them looked for differences in birth weight between offspring of mothers who were exposed to famine in either early or late gestation. The authors found that individuals who were exposed to famine in early gestation had epigenetic differences but a normal birth weight. In contrast, individuals exposed to famine in late gestation had a low birth weight but did not have any epigenetic changes [58]. At the same time, other studies have demonstrated that those individuals exposed to famine during the gestational period have a higher risk of developing schizophrenia and dyslipidemia. One of these studies demonstrated that there are sexspecific differences in the pattern of atherogenic lipids at the age of 58. Women showed elevated serum concentrations of total cholesterol, low-density lipoprotein (LDL), and triglycerides in comparison to unexposed women [61, 62]. It was also found that exposed women had a wide range of body mass indexes and thus have a higher risk of obesity and developing chronic diseases [63-65]. Other studies have shown that individuals exposed to famine in early gestation, both males and females, have an increased risk of schizophrenia while individuals who were exposed in later gestation have a higher risk of developing affective disorders [66-68].

\section{Epigenetic Mechanisms}

There are different epigenetic mechanisms that regulate gene expression whether this is to activate or repress it: DNA methylation, histone modification, nucleosome positioning, and RNA interference (RNAi) (miRNAs and small interfering RNA (siRNAs)) [4]. It is important to mention that all these epigenetic mechanisms act together at the same time and not separately to regulate gene expression.

2.1. DNA Methylation. There are evidence that DNA methylation occurs in different regions of the genome and it has great importance in embryogenesis, cellular differentiation, and tissue-specific development. It is noteworthy that DNA methylation varies among tissues and cell type because it is a dynamic process involving methylation and demethylation events [69-71] and plays a role in normal regulatory functions. Therefore, a dysfunction of normal state DNA methylation would lead to disease. Methylation is mediated by the DNA methyltransferase (DNMTs) family which is responsible for donating a methyl group to the DNA 5cystosine. This family of enzymes has 5 members: DNMT1, DNMT2, DNMT3a, DNMT3b, and DNMT3L. At the same time, DNMTs can be classified into de Novo and maintenance DNMTs (Figure 2) [4]. De Novo DNMTs are DNMT3a, and DNMT3b and they are responsible for methylation during embryonic development. DNMT1 is the maintenance DNMT which is responsible for methylate hemimethylated sites that are generated during DNA replication. DNMT2 acts on transfer RNA, and DNMT3L acts on embryogenesis [72].

The other mechanism that counteracts DNA methylation is demethylation. Demethylation can be passive or active [4]. The first is induced by inhibition of DNMTs activities such as in the case of several drugs that are used as therapeutic compounds to eliminate aberrant hypermethylation. Active demethylation, in turn, occurs in cell differentiation and has been found in the activation of immune cells [73]. This process depends on the action of cytosine deaminase, which, when it is activated, induces cytidine deaminase (AICDA) that deaminates 5-methylcytosine [74].

It is important to understand that when there is a methylation state, transcription will be repressed; in contrast, when there is an unmethylated state, transcription will be permitted. Transcription inhibition is achieved because methyl groups interfere with the binding of transcription factors that activate transcription from a specific gene. Many of these transcription factors recognize mainly $\mathrm{CpG}$ sequences, but when these sequences are methylated, they are unable to bind DNA. An additional mechanism of transcriptional repression involves proteins that are attracted to methylated $\mathrm{CpG}$ sequences. These protein families are part of the methyl-CpG-binding domain (MBD), and they recognize methylated sequences thus providing a further signal to alter chromatin structures by formation of a corepressor complex [75].

There are four possible DNA methylation patterns. The first methylation pattern and the most widely studied is the methylation of $\mathrm{CpG}$ islands at promoter regions of genes. These CpG islands are regions of more than 200 bases with a $\mathrm{G}+\mathrm{C}$ content of at least $50 \%$. Many human gene promoters $(60 \%)$ are associated with CpG islands and their basal state must be unmethylated to allow transcription (Figure 3(a)) $[75,76]$. The second pattern is DNA methylation of CpG island shores, which are regions of lower CpG density in close 


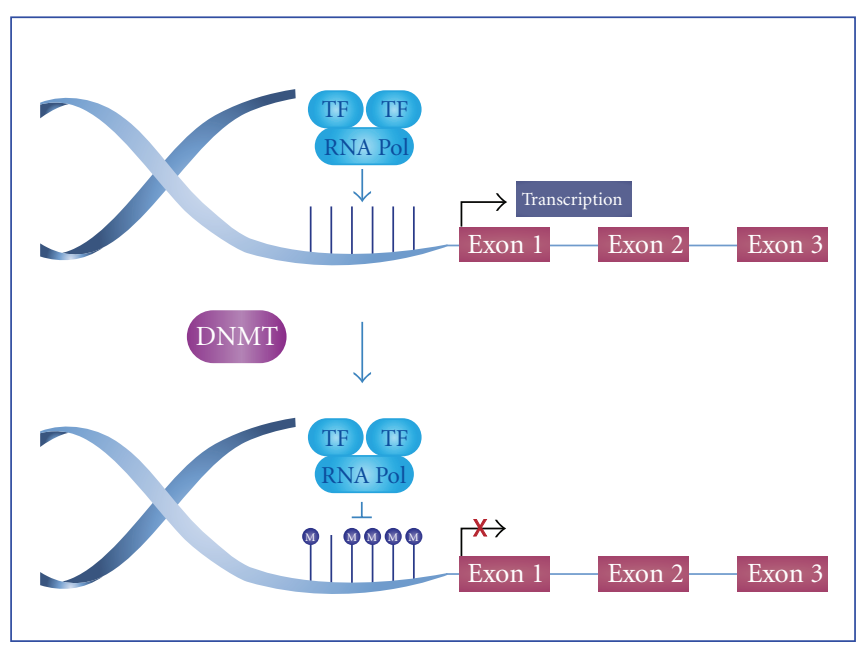

(a)

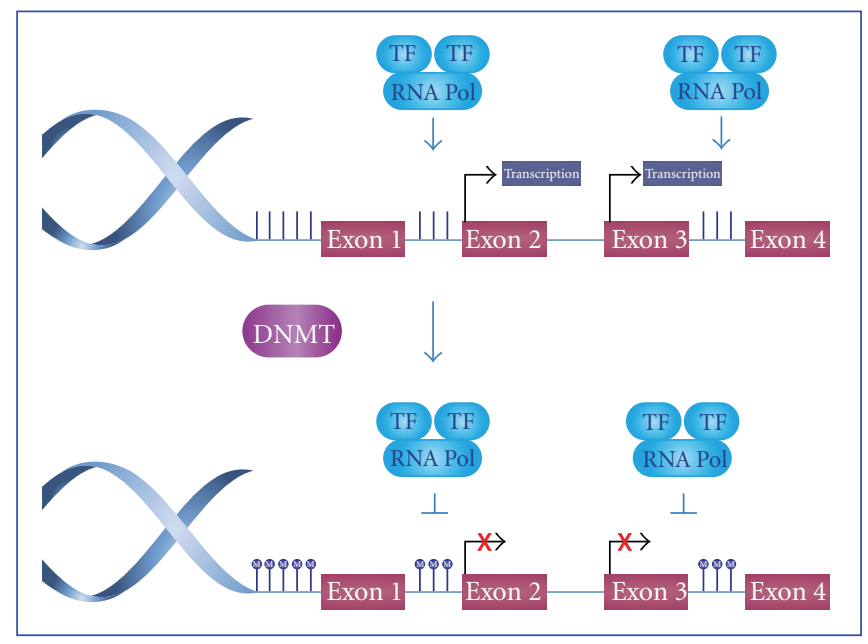

(c)

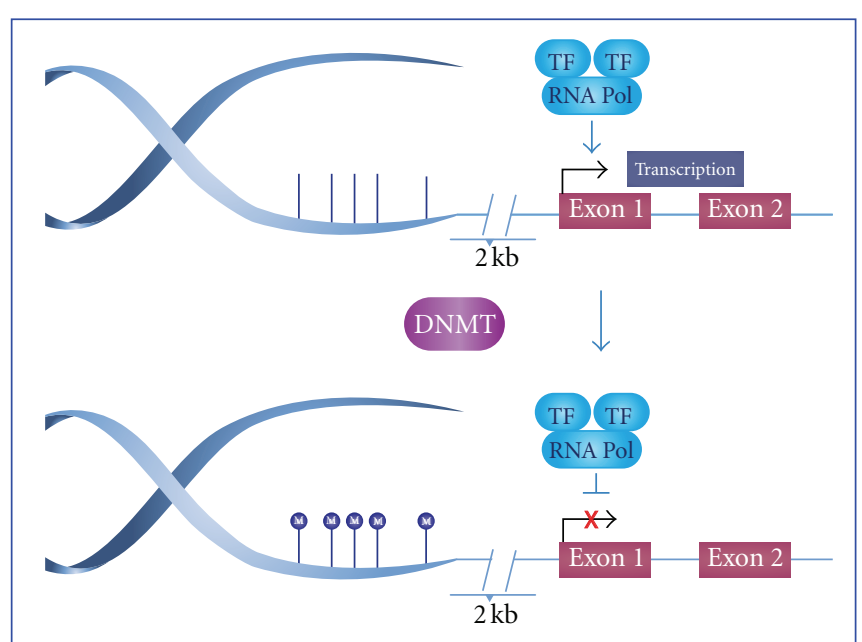

(b)

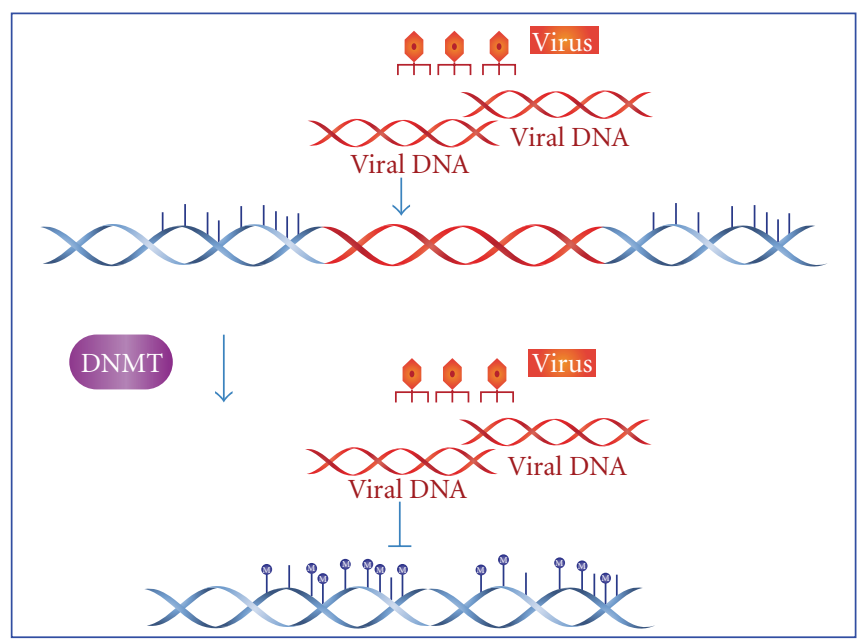

(d)

Figure 3: DNA methylation patterns. (a) In basal state, CpG Islands are unmethylated to allow the transcription, but when they are methylated at promoter regions of genes, the transcription will be inhibited. (b) At the same time, CpG island shores (located up to $\sim 2 \mathrm{~kb}$ from CpG islands) have a methylation pattern that is similar to the CpG islands in that methylation is closely associated with transcriptional inactivation. (c) Gene bodies are methylated to prevent spurious transcription initiations. (d) Repetitive sequences which are hypermethylated to protect chromosomal integrity by preventing reactivation of endoparasitic sequences that cause chromosomal instability.

proximity ( $\sim 2 \mathrm{~kb}$ ) to CpG islands. This pattern is similar to the $\mathrm{CpG}$ island methylation pattern in which methylation is closely associated with transcriptional inactivation. It is important to note that most of the tissue-specific DNA methylation occurs in these regions (Figure 3(b)) $[75,77]$.

In contrast with both mechanisms mentioned above, the third pattern occurs in gene bodies which, in their basal state, are methylated to facilitate correct transcription thus preventing spurious transcription initiations (Figure 3(c)) [78]. In disease, gene bodies are demethylated to allow transcription to be initiated at incorrect sites. DNA methylation can also take place in $\mathrm{CHG}$ and $\mathrm{CHH}(\mathrm{H}=\mathrm{A}$, $\mathrm{C}$ or $\mathrm{T}$ ) sites in the human genome. This methylation has been found predominantly in stem cells and seems to be enriched in gene bodies directly correlated with gene expression. The last pattern to mention is hypermethylation of repetitive sequences that protect chromosomal integrity by preventing reactivation of endoparasitic sequences that cause chromosomal instability, translocations, and gene disruption (Figure 3(d)) [79].

2.2. Histone Modifications. Histones are conserved proteins that package and organize DNA. These proteins can be grouped in core histones (H2A, H2B, H3, and H4) and linker histones ( $\mathrm{H} 1$ and $\mathrm{H} 5)$. The linker histones bind to the DNA by sealing off the nucleosome at the location where DNA enters and leaves [80].

Histones suffer some posttranslational modifications such as lysine acetylation, and methylation, phosphorylation, ubiquitination, SUMOylation, and ADPribosylation. Histone modifications play an important role in transcriptional 

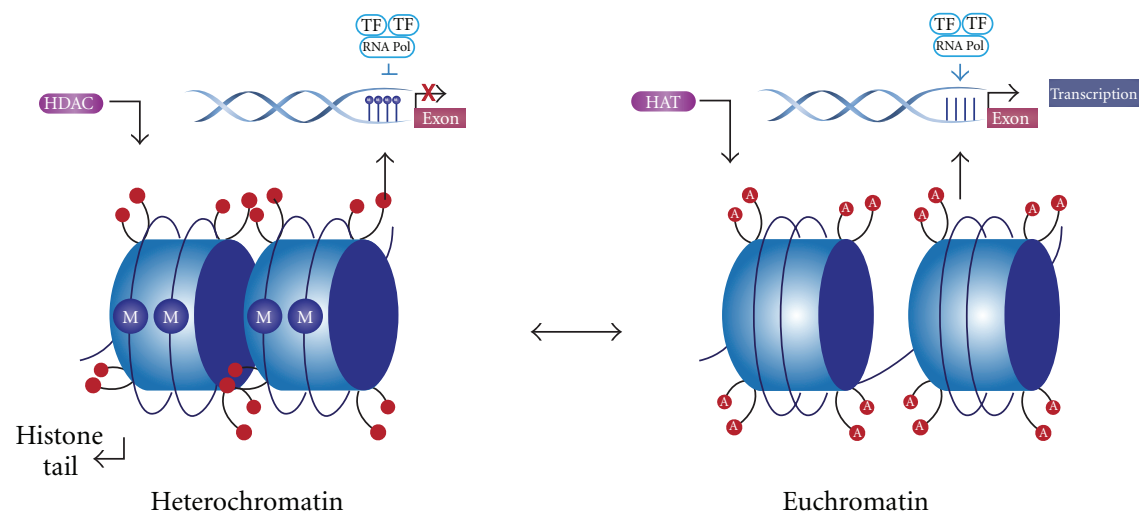

Euchromatin

FIGURE 4: Histone modification. To form heterochromatin, histone deacetylation of histone tails caused by HDACs enzymes in association with DNA methylation $(\mathrm{M})$ confers a dense configuration of DNA that prevents its transcription. In the euchromatin state, there is an acetylation of histone tails (A) by HATs enzymes in association with DNA demethylation to promote gene expression.

regulation, DNA repair, DNA replication and chromosome condensation $[80,81]$. Of all these modifications, the one most widely studied is lysine acetylation. In this process, histones are acetylated and deacetylated on lysine residues in the $\mathrm{N}$-terminal tail. These reactions are catalyzed by histone acetyltransferases (HATs), or histone deacetylases (HDACs) respectively $[82,83]$. HATs promote gene expression by transferring an acetyl group to lysine and HDACs promote gene repression by removing an acetyl group from the lysine tail (Figure 4).

An example of how these modifications affect transcriptional regulation is the histone deacetylation with the association of $5^{\prime}$ methylcytosine in the DNA, which confers a heterochromatin configuration that makes DNA inaccessible to transcription factors. On the other hand, acetylation of histone tails such as lysine acetylation on histone 3 (H3K9) and DNA demethylation causes euchromatin configuration, which is accessible to transcription machinery [84]. It is important to mention that many posttranslational modifications can occur on the same histone tail and at same time produce the repression or the activation of gene expression [85]. For example, during cell cycle there is a regulatory relationship between methylation of $\mathrm{H} 3 \mathrm{~K} 9$ and phosphorylation of $\mathrm{H} 3$ serine 10 (H3S10). Phosphorylation of H3S10 is required for chromosomal condensation. During early prophase and anaphase, there are high quantities of H3S10 phosphorylation. In contrast, during late anaphase, dephosphorylation occurs and $\mathrm{H} 3 \mathrm{~K} 9$ methylation reemerges. Therefore, H3S10 phosphorylation blocked methylation of H3K9, which gave transcription factors access to DNA during mitosis. Also phosporylation preserves methylation patterns during cell division [86].

2.3. Nucleosome Positioning. Nucleosomes are a complex form of DNA packaged by histones. There are nucleosome positioning patterns that play an important role in transcriptional regulation. Depending on how close nucleosomes are to transcription start sites (TSSs), they may block the activators' and transcription factors' access to the DNA strand thus inhibiting elongation of the transcripts. Active gene promoters have a nucleosome-free region at the $5^{\prime}$ and $3^{\prime}$ untranslated region (UTR) to facilitate the assembly and disassembly of the transcription machinery [87]. For example, nucleosome displacements of as few as $30 \mathrm{bp}$ at TSS have been implicated in changes in the activity of RNA polymerase II. When there is a loss of a nucleosome upstream from the TSS, transcription factors can bind to the TSSs and gene expression is achieved. In contrast, when there is an occlusion of the TSS by a nucleosome, transcription machinery does not bind to the TSSs and gene repression occurs. Interestingly, nucleosome positioning can influence DNA methylation because DNA methyltransferases preferentially target nucleosome-bound DNA [88].

2.4. microRNAs. miRNAs are RNAs that are 18-23 nucleotides in length and function as posttranscriptional regulators. They regulate mRNA translation by binding to complementary sequences that are cut or repressed. Many miRNAs are transcribed from intergenic regions or from introns of protein-coding genes and, sometimes, they are expressed at the same time that the protein gene is transcribed. Just a few miRNAs have been located in exons of protein-coding genes. Of all these miRNAs, the intergenic miRNAs are the only ones which have their own gene promoter and regulatory region [89].

The translational repression and target degradation of mRNAs is achieved by the level of complementarity between miRNA strands and the site in the $3^{\prime}$ UTR targets. If there is complete complementation, there will be cleavage of the mRNAs and this will produce degradation. On the other hand, if there is incomplete complementation, translation will be prevented by taking the transcripts into $\mathrm{P}$ bodies to keep them silenced using proteins that prevent translation or removal of the cap structure (Figure 5). Another mechanism by which miRNAs affect gene expression is by histone modification and DNA methylation of promoter sites. This mechanism occurs thanks to the RNA-induced transcriptional silencing (RITS) complex. This protein complex binds to miRNAs to perform posttranslational modification of histone tails such as methylation of $\mathrm{H} 3 \mathrm{~K} 9$ to form 


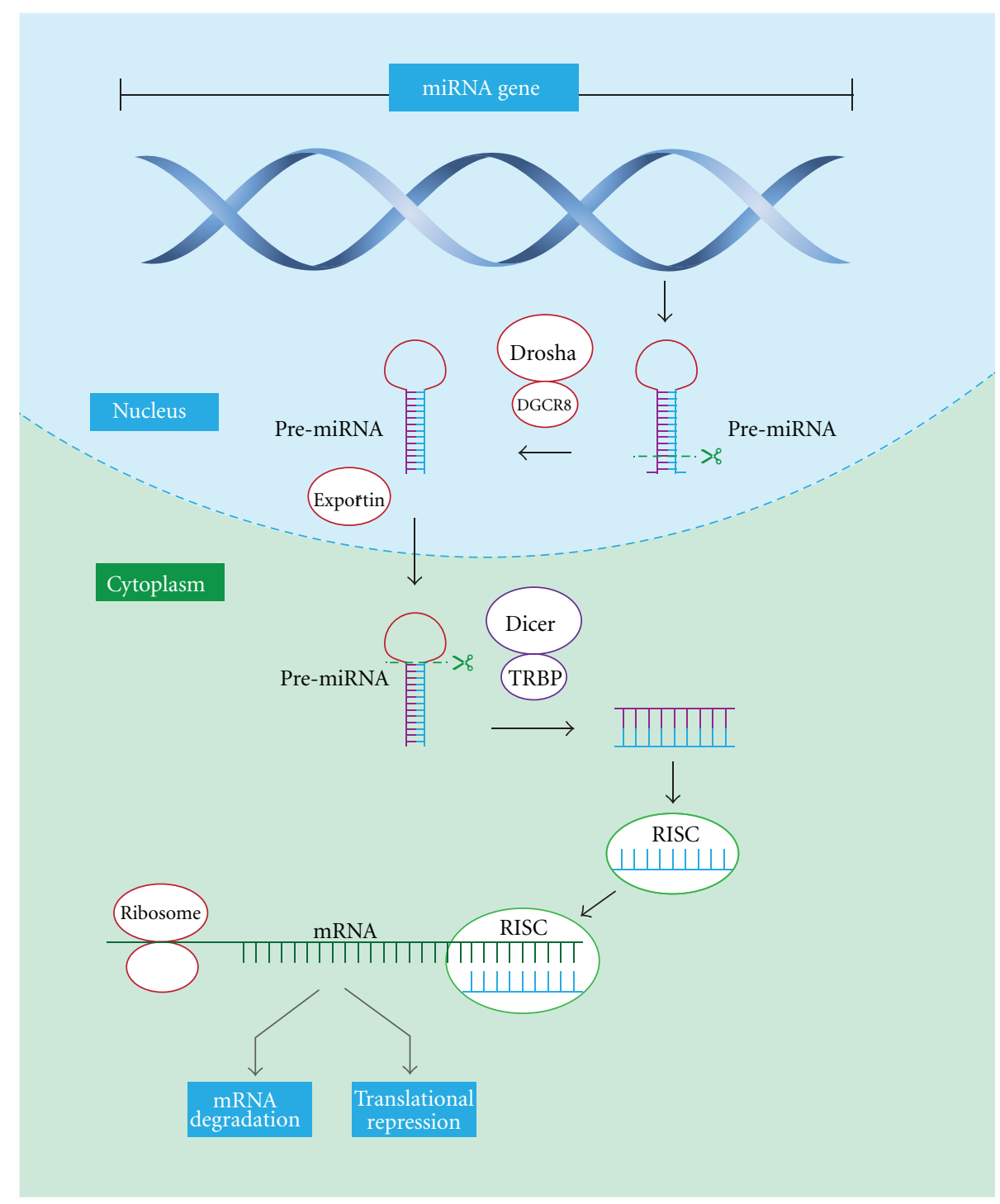

FIgURe 5: miRNA biogenesis. miRNA genes are transcribed by RNA Polymerase II in the nucleus to form a primary miRNA (pri-miRNA) that is, 100 to 1000 nucleotides in length. This pri-miRNA is recognized by nuclear enzymes Drosha, Pasha, or DGCR8 (in humans), which cleave about 11 nucleotides off of it to produce hairpin structures known as pre-miRNA, which are $~ 70$ nucleotides in length. Once pre-miRNA hairpins are made, they are exported from the nucleus to the cytoplasm by the Exportin-5 enzyme. In the cytoplasm, the Dicer enzyme cleaves pre-miRNAs to form a duplex miRNA that is 18-23 nucleotides in length. Of these 2 strands, the one with lower stability in the $5^{\prime}$ end is the guide strand, and it will be associated with the RNA-induced silencing complex (RISC), where miRNAs interact with the mRNA targets. The RISC complex needs to interact with other proteins such as Argonaute (Ago) proteins and TRBP to function appropriately. The translational repression and target degradation of mRNAs can be achieved by the level of complementarity between miRNAs strand and the site in the $3^{\prime}$ UTR targets. If there is a complete complementation, there will be a cleavage of the mRNAs and it will produce the degradation. On the other hand, if there is an incomplete complementation, translation will be repressed by taking the transcripts into $\mathrm{P}$ bodies to keep them silenced.

heterochromatin and to cause transcriptional repression $[89,90]$.

\section{Epigenetics and Autoimmunity}

Autoimmune diseases are a complex group of diseases that do not have the same epidemiology, pathology, or symptoms but do have a common origin [91]. All autoimmune diseases share immunogenetic mechanisms mediated in part by several pleiotropic genes. Many studies over the years have shown that these diseases are caused by alterations in many loci and genes in the human genome [92]. However, until recent years, epigenetic studies have focused on autoimmune diseases. Therefore, it is important to underline the fact that autoimmune diseases may be generated by several alterations in the same epigenetic mechanism. Also, it is essential to understand that epigenetics is not the only mechanism 
that may cause autoimmunity. In fact, there are intrinsic and extrinsic components (mutations, polymorphisms, and environmental factors) that predispose to autoimmunity.

3.1. DNA Methylation and Autoimmune Diseases. As was mentioned at the beginning of this paper, DNA methylation is the most widely studied mechanism in autoimmune diseases. Several studies done so far have found that some diseases such as systemic lupus erythematosus (SLE) and rheumatoid arthritis (RA) have global hypomethylation in the cells they target in promoter regions of DNA (Table 2). Studies of other autoimmune diseases in search of methylation patterns are just beginning.

3.1.1. Systemic Lupus Erythematosus. SLE is a systemic multiorgan autoimmune disease characterized by autoantibody response to nuclear and/or cytoplasmic antigens. Several studies have shown that there is a global hypomethylation of promoter regions, which contain the genes that are overexpressed in the disease such as ITGAL, CD40LG, PRF1, CD70, IFGNR2, MMP14, LCN2, and in the ribosomal RNA gene promoter (18S and 28S) [23-27]. The DNA hypomethylation may also affect the chromatin structure of T-cells thus enhancing the overexpression of these genes. This gene overexpression will cause cell hyperactivity, perpetuation of the immune response and consequently, and perpetuation of inflammatory response [93-95].

An example of how hypomethylation alters gene expression in SLE is the hypomethylation of the E1B promoter of CD5 in resting B cells. CD5 is a protein found in B cells that serves to mitigate activating signals from the $B$ cell receptor (BCR) so that B cells are only activated by strong stimuli and not by normal tissue proteins. CD5 has two isoforms: E1A that is expressed on the membrane and E1B that is retained in the cytoplasm. The hypomethylation of E1B promoters may be the consequence of a reduced expression of DNMT1. Therefore, there is an increase in the expression of this CD5 isoform that will cause impairment of cell receptor signaling, which will then promote autoimmunity [28].

Another example is in the Lupus like disease caused by procainamide and hydralazine. These two drugs are DNA methylation inhibitors. As a result, they produce hypomethylation of DNA [96]. Procainamide is a competitive inhibitor of DNMT1 [97]. In contrast, hydralazine inhibits $\mathrm{T}$ and B cell signal-regulated kinase pathways [98]. The kinase signaling pathway plays an important role in the regulation of methylation [99]. These two mechanisms produce a reduction in DNMTs that will enhance the genetic expression of adhesion molecules on lupus-drug-induced lymphocytes [100-102].

3.1.2. Rheumatoid Arthritis. RA is a disease characterized by the progressive destruction of joints by invasive synovial fibroblasts. The RA synovial fibroblasts (RASFs) play a major role in the initiation and perpetuation of the disease [103]. They are the reason why several epigenetic studies of RA are focused on these synovial cells. Researchers have found a global hypomethylation of these cells, which could be responsible for the overexpression of inflammatory cytokines in synovial fluid [104, 105].

Some examples of hypomethylation in RA are in $\mathrm{CpG}$ islands upstream of an L1 open-reading frame and the Interleukin-6 (IL-6) promoter gene in monocytes. L1 is one of the major classes of repetitive elements that are spread throughout the genome. They are used as markers because they are methylated in normal synovial tissue. In synovial tissue from patients with RA, L1 is hypomethylated as a consequence of reduced expression of DNMTs. This reduction of methylation in inflammatory response promoter genes causes an overexpression of growth factors and receptors, adhesion molecules, and cytokines. In the end, they will cause irreversible phenotypic changes in synovial fibroblasts $[29,106]$.

The other example is the hypomethylation in $\mathrm{CpG}$ islands within the IL- 6 promoter gene in monocytes. IL6 is a proinflammatory cytokine that participates in B cell response. When this promoter is hypomethylated, there is an overexpression of IL- 6 that will cause an overexpression of pro-inflammatory cytokines at the same time. This will be associated with a local hyperactivation of the inflammation circuit [30]. But there is evidence that we can also find a hypermethylation mechanism in monocytes such as in the case of the CpG islands within the promoter of death receptor 3 (DR-3). DR-3 is a protein that causes apoptosis and activation of transcription factor NF-kappa-B (NF- $\kappa \mathrm{B})$. However, when there is a downregulation of this protein because of the hypermethylation of its promoter, the RA synovial cell will be resistant to apoptosis $[31,107,108]$.

3.1.3. Type 1 Diabetes (T1D). T1D is a T-cell-mediated autoimmune disease that develops in genetically susceptible individuals and affects their endocrine pancreas. There are some mechanisms by which epigenetics may play an important role in T1D by modulating lymphocyte maturation and cytokine gene expression and by differentiation of subtype $\mathrm{T}$ helper cells ruled by epigenetic controls. In this autoimmune disease, in contrast to SLE and RA, there is a global hypermethylation activity caused by altered metabolism of homocysteine [109].

Glucose and insulin levels are determinants of methylation [32]. They alter homocysteine metabolism by increasing cell homocysteine production through its inhibition of transsulfuration $[110,111]$. When there is an increase in the levels of homocysteine, methionine in cells will be catalyzed by DNMTs in S-adenosylmethionine. This will enhance DNMT activity that will subsequently lead to increased global DNA methylation. Also, an increase in maternal homocysteine during pregnancy as a result of a low protein diet can produce an altered methionine metabolism that will cause a decrease in islet mass and vascularity in the fetus with a subsequent glucose intolerance in adult life $[112,113]$.

3.1.4. Multiple Sclerosis (MS). MS is a chronic inflammatory disease characterized by myelin destruction followed by a progressive degree of neurodegeneration. Recent studies have shown that the promoter region of peptidyl arginine 
TABLE 2: Summary of epigenetic mechanisms involved in autoimmune diseases.

\begin{tabular}{|c|c|c|}
\hline \multicolumn{3}{|c|}{ DNA methylation } \\
\hline \multirow{10}{*}{$\begin{array}{l}\text { Systemic lupus } \\
\text { eErithematosus }\end{array}$} & Global Hypomethylation of promoter region of genes: & References \\
\hline & ITGAL & {$[23]$} \\
\hline & CD40LG & {$[24]$} \\
\hline & PRF1 & {$[25]$} \\
\hline & CD70 & {$[26]$} \\
\hline & IFGNR2 & {$[27]$} \\
\hline & MMP14 & {$[27]$} \\
\hline & LCN2 & [27] \\
\hline & Ribosomal RNA gene promoter (18S and 28S) & {$[27]$} \\
\hline & e1B promoter of CD5 in resting B cells & {$[28]$} \\
\hline \multirow{5}{*}{ Rheumatoid arthritis } & Hypomethylation: & \\
\hline & CpG islands upstream of an $\mathrm{L} 1$ open-reading frame & [29] \\
\hline & IL-6 promoter gene in monocytes & {$[30]$} \\
\hline & Hypermethylation: & \\
\hline & Promoter of death receptor 3 (DR-3) & {$[31]$} \\
\hline Type 1 diabetes & Global hypermethylation by altered metabolism of homocysteine & {$[32]$} \\
\hline Multiple sclerosis & $\begin{array}{l}\text { Hypomethylation of promoter region of peptidyl arginine deiminase } \\
\text { type II (PAD2) }\end{array}$ & {$[33]$} \\
\hline Systemic sclerosis & Hypermethylation of CpG islands in Fli1 promoter & {$[34]$} \\
\hline \multicolumn{3}{|c|}{ Histone modification } \\
\hline \multirow{6}{*}{$\begin{array}{l}\text { Systemic lupus } \\
\text { erithematosus }\end{array}$} & Predisposition to apoptotic nucleosomes & \\
\hline & $\mathrm{H} 3 \mathrm{~K} 4 \mathrm{me} 3$ & \\
\hline & $\mathrm{H} 4 \mathrm{~K} 8$ triacetylation & \\
\hline & $\mathrm{H} 3 \mathrm{~K} 27 \mathrm{me} 3$ & {$[35]$} \\
\hline & $\mathrm{H} 2 \mathrm{BK} 12 \mathrm{ac}$ & \\
\hline & Global acetylation of histone $\mathrm{H} 3$ and $\mathrm{H} 4$ in active CD4+ T cells & {$[36]$} \\
\hline \multirow{4}{*}{ Rheumatoid arthritis } & HDAC inhibitors: & \\
\hline & Block induction of MMPs & {$[37]$} \\
\hline & Repress of ADAMTs enzymes & \\
\hline & Hyperacetylation of histones induces p16 and p 21 & {$[38]$} \\
\hline \multirow{7}{*}{ Type 1 diabetes } & Increase $\mathrm{H} 3 \mathrm{~K} 9 \mathrm{me} 2$ in lymphocytes genes: & \\
\hline & CLTA4 & \\
\hline & TGF-B & \\
\hline & $\mathrm{NF}-\kappa \mathrm{B}$ & {$[39]$} \\
\hline & p38 & \\
\hline & IL-6 & \\
\hline & Hyperglcemia causes $\mathrm{H} 3 \mathrm{~K} 4$ and $\mathrm{H} 3 \mathrm{~K} 9$ methylation & {$[40]$} \\
\hline Multiple sclerosis & Hyperacetylation of $\mathrm{H} 3$ promoter region in white matter & {$[41]$} \\
\hline \multicolumn{3}{|c|}{ miRNAs } \\
\hline \multirow{6}{*}{$\begin{array}{l}\text { Systemic lupus } \\
\text { Erithematosus }\end{array}$} & Decreased expression: & \\
\hline & $\operatorname{miR}-146 a$ & {$[42]$} \\
\hline & $\operatorname{miR}-125 a$ & {$[43]$} \\
\hline & Upregulation: & \\
\hline & miR-21 and miR-148a & {$[44]$} \\
\hline & $\operatorname{miR}-155$ & {$[45]$} \\
\hline
\end{tabular}


TABle 2: Continued.

DNA methylation

\begin{tabular}{lll}
\hline & \multicolumn{1}{c}{ DNA methylation } & \\
\hline & Overexpression: & {$[46]$} \\
miR-155 & {$[47]$} \\
miR-203 & {$[48]$} \\
& miR-146 & {$[49]$} \\
& Decreased expression of miR-124 & \\
& Upregulation: & {$[50]$} \\
& miR-326 & {$[51]$} \\
& miR-34a & {$[51]$} \\
Multiple sclerosis & miR-155 & {$[52]$} \\
& Expression in Treg cells: miR-17-5p, miR-497, miR-193 and miR-126 & {$[53]$} \\
& Disease Relapse: miR-18b and miR-599 & {$[54]$} \\
\hline Disease Remission: miR-96 & {$[55]$} \\
Brain-specific: miR-124 & {$[55]$} \\
\hline \multirow{2}{*}{ Type 1 diabetes } & Overexpression of miRNA-510 & {$[56]$} \\
\hline \multirow{2}{*}{ Sjögren's syndrome } & Decreased expression of miRNA-342 and miRNA-191 & {$[57]$} \\
& Beta cell failure: miR-21, miR-34a, and miR-146a & {$[57]$} \\
\hline
\end{tabular}

deiminase type II (PAD2) is hypomethylated [33]. PAD2 plays a key role in the citrullination process of myelin basic protein (MBP). This citrullination process has important biologic effects. It promotes protein autocleavage, which increases the probability of creating new epitopes and also modulates the immune response. In MS, an increase has been found in demethylase enzyme activity, which will cause hypomethylation of the PAD2 promoter region [114]. Because of this hypomethylation, there will be an overexpression of PAD2 that will increase the MBP citrullination process with a subsequent increase in the production of immunodominant peptides. These peptides will increase the autocleavage of MBP thereby causing irreversible changes in its biological properties, which will produce proteolytic digestion, myelin instability, and a chronic inflammation response [115-117].

3.1.5. Systemic Sclerosis (SSc). SSc is a rare condition of unknown etiology that is characterized by excessive collagen deposits on skin and other tissues with a progressive vasculopathy. In SSc, there is a hypermethylation of $\mathrm{CpG}$ islands in the Fli1 promoter, which is a transcription factor that inhibits collagen production. The reduced expression of Flil increases collagen synthesis, that will not be balanced by metalloproteinase activity. This promotes collagen accumulation and, subsequently, the tissue fibrosis that is a characteristic of the disease $[34,118]$.

\subsection{Histone Modifications and Autoimmune Diseases}

3.2.1. Systemic Lupus Erythematosus. Histone modifications in SLE have been studied in murine models and in humans.
These studies have found that, during apoptosis, histones can be modified to make them immunogenic. It is noteworthy that in the pathogenesis of SLE, antibodies are directed against components of the cell nucleus that are exposed at the cell surface during apoptosis $[119,120]$.

The nucleosomes, the primary inciting antigen in SLE, are released in patients with SLE as a result of a disturbed apoptosis or an insufficient clearance of apoptotic debris. During apoptosis, the nucleosome is modified, thereby creating more immunogenic epitopes. Subsequently, epitope spreading will lead to the formation of autoantibodies against unmodified chromatin components [35, 121]. Histone modifications such as histone 3 lysine 4 trimethylation (H3K4me3), histone 3 lysine 8 (H4K8) triacetylation, histone 3 lysine 27 trimethylation ( $\mathrm{H} 3 \mathrm{~K} 27 \mathrm{me} 3)$, and histone $2 \mathrm{~B}$ lysine 12 acetylation (H2BK12ac) will cause an increase in apoptotic nucleosomes (Table 2). These apoptotic nucleosomes will generate autoimmunogenicity that will cause activation of antigen-presenting cells and autoantibody production with a subsequent inflammatory response [36, 122].

There are other studies that have shown a global acetylation pattern of histone $\mathrm{H} 3$ and $\mathrm{H} 4$ in active SLE CD4+ $\mathrm{T}$ cells [123]. Also, monocytes, which are important in SLE renal disease, have been shown to have an altered acetylation pattern of histone $\mathrm{H} 4$ thus increasing the expression of interferon (IFN) genes that play a key role in SLE pathogenesis [124-126].

3.2.2. Rheumatoid Arthritis. RA synovial tissue is characterized by an imbalance between HAT and HDAC activity. Cartilage destruction is thought to be mediated by matrix metalloproteinases (MMPs) and enzymes from the ADAMTS 
(a disintegrin and metalloproteinase domain with thrombospondin motifs) family. Many of these genes are regulated by modifications in the chromatin including acetylation of histones [127-129].

Many studies have shown that HDAC inhibitors inhibit cartilage degradation by blocking the induction of key MMPs by proinflammatory cytokines at both the mRNA and protein levels. Also, ADAMTs enzymes are inhibited at the mRNA level [37]. In fact, hyperacetylation of synovial cell histones induces p16 and p21 (cyclin-dependent kinase inhibitors that regulate cell cycle) expression with a subsequent decrease in Tumor Necrosis Factor-alpha (TNF- $\alpha$ ) synthesis (Table 2). These mechanisms will inhibit joint swelling, synovial inflammation, and joint destruction in murine RA models $[38,129]$. Also, the hyperacetylation of histones will downregulate HIF-1a (hypoxia inducible factor) and vascular endothelial growth factor (VEGF) to block angiogenesis in synovial cells [130].

It is noteworthy that HDAC inhibitors may, therefore, be new chondroprotective therapeutic agents in arthritis due to their ability to inhibit the expression of destructive metalloproteinases and ADAMTs in synovial tissue [131-133].

3.2.3. Type 1 Diabetes. There are just a few epigenetic studies associated with histone modifications and the pathogenesis of T1D. Patients with T1D show a subset of genes with an increase in histone 3 lysine 9 dimethylation (H3K9me2) in lymphocytes. This subset of genes includes the CLTA4, which is a type 1 diabetes susceptibility gene and has increased methylation of $\mathrm{H} 3 \mathrm{~K} 9$ in its promoter region. Other genes that have altered $\mathrm{H} 3 \mathrm{~K} 9 \mathrm{me} 2$ are transforming growth factor-beta (TGF-B), NF- $\kappa$ B, p38 (mitogen-activated protein kinase), toll-like receptors (TLRs), and IL-6 (Table 2). The transcription factor NF- $\kappa \mathrm{B}$ is also upregulated by $\mathrm{H} 3 \mathrm{~K} 4$ methyltransferase thus causing an increase in inflammatory gene expression in diabetic mice. All these genes are associated with autoimmune and inflammation-related pathways $[39,134,135]$.

Histone modifications are also among the mechanisms that cause cardiovascular complications in T1D patients. Chemical modification of the H3K4 and H3K9 has recently been found to be related to the gene expression conferred by hyperglycemia. Transient hyperglycemia promotes geneactivating epigenetic changes and signaling events critical in the development and progression of vascular complications. These epigenetic changes are $\mathrm{H} 3 \mathrm{~K} 4$ and $\mathrm{H} 3 \mathrm{~K} 9$ methylation in genes associated with vascular inflammation $[40,136,137]$.

3.2.4. Multiple Sclerosis. The oligodendrocyte identity is modulated by posttranslational modifications of histones. In rodents, histone deacetylation produces oligodendrocyte differentiation, whereas acetylation is associated with transcriptional inhibitors of differentiation. In patients with MS, there is a shift toward histone acetylation in the white matter. Thus, hyperacetylation of $\mathrm{H} 3$ in the promoter region of inhibitory genes will produce high levels of transcriptional inhibitors of oligodendrocyte differentiation such as TCF7L2, ID2, and SOX2 (Table 2) [41].

3.3. Nucleosome Positioning and Autoimmune Diseases. Not many studies have been done on how nucleosome positioning causes autoimmune diseases. But in RA, histone variant macroH2A interferes with the binding of transcription factor NF- $\kappa \mathrm{B}$ and impedes the action of some proteins that restructure nucleosomes [66]. Also, it has been reported that an SNP in the 17q12-q21 region, which is associated with a high risk of T1D, Crohn's disease, and Primary Biliary Cirrhosis, leads to allele-specific differences in nucleosome distribution [138].

\section{4. microRNAs and Autoimmune Diseases}

3.4.1. Systemic Lupus Erythematosus. Studies have shown that most lupus-related genes contain at least one miRNA target site for more than hundred miRNAs. In SLE, there is evidence of the key role some miRNAs play in its pathogenesis (Table 2). For example, miR-146a is a negative regulator of TLR signaling and its expression is decreased in patients with SLE. Also, this miRNA is a negative regulator of type I IFN pathway and carries out its function by targeting IFN regulatory factor 5 (IRF-5) and STAT-1 (Signal transduction and transcription protein). Therefore, decreased expression of miR-146a in peripheral blood mononuclear cells (PBMCs) may contribute to the enhanced type I IFN production in SLE [42]. Other studies have found that miR125 a was reduced in patients with lupus. This miRNA is expressed in T cells and is a critical transcription factor in the regulation of the chemokine RANTES (Regulated upon Activation, Normal T-cell Expressed, and Secreted). The decreased expression of miR-125a results in the upregulation and elevation of the inflammatory chemokine RANTES in lupus $\mathrm{T}$ cells [43].

Additional studies identified the upregulation of miR21 and miR-148a in CD4+ $\mathrm{T}$ cells. One way these miRNAs may act in SLE is through the production of states of hypomethylation of some promoters by repressing DNMTs, which increases the expression of autoimmuneassociated methylation-sensitive genes, CD70, and lymphocyte function-associated antigen [44]. Another way would be to inhibit DNMT1 translation via interaction with its $3^{\prime}$ UTR, as is the case with miR-126 [139]. There are other miRNAs that regulate $\mathrm{B}$ and $\mathrm{T}$ cell immunity such as miR155. Therefore, the upregulation of miR-155 in lupus B and $\mathrm{T}$ lymphocytes may lead to abnormal B-cell activation and abnormal inflammatory T-cell development and cytokine production in patients with lupus $[45,46]$.

3.4.2. Rheumatoid Arthritis. miRNAs are also critical for RA pathogenesis (Table 2). For example, miR-155 and miR-146 are overexpressed in RASFs. miR-155 expression is enhanced by TNF- $\alpha$ and interleukin-1beta (IL-1B), and this enhancement produces an inhibitory effect on metalloproteinase expression in synovial fibroblasts [47]. In addition, miR146 is an miRNA that is upregulated by proinflammatory 
cytokines and its function is to downregulate the NF- $\kappa \mathrm{B}$ pathway in monocytes. This miRNA has a strong correlation with the levels of TNF- $\alpha$ and interleukin-17 (IL-17) [48, 140, 141]. Another miRNA in RA is miR-203, which also causes repression of several metalloproteinase and inhibition of IL-6 [142].

Another miRNA implicated in RA is miR-124, which targets cyclin-dependent kinase 2 (CDK-2). In the basal state, CDK2 represses cell proliferation and arrests the cell cycle at the G1 phase, but in pathologic conditions such as RA, its level decreases. miR-124 also targets monocyte chemoattractant protein 1 (MCP-1), which is responsible for mononuclear phagocytes into the joint. Thus in RA, this miRNA increases cell proliferation and MCP-1 production $[49,143]$.

3.4.3. Multiple Sclerosis. Currently, many studies have been focusing on miRNAs involved in MS pathogenesis (Table 2). A recent study found that miR-326 plays a critical role in the pathogenesis of MS since it upregulates the Th-17 cell differentiation by targeting Ets-1, which is a negative regulator of Th-17 differentiation. This miRNA was significantly upregulated in patients with relapsing-remitting MS which produced an increase in Th-17 cell numbers and more severe symptoms [50]. Other miRNAs involved in MS are miR-34a and miR-155, which are upregulated in active MS lesions and contribute to MS pathogenesis by targeting CD47. CD47 is a "don't eat me" signal, and macrophages with low levels of this molecule are released from the inhibitory control signal, which causes increased phagocytosis of myelin. Also, miR155 promotes development of inflammatory Th1 and Th17 cells [51].

In addition, differentially expressed miRNAs such as miR-17-5p, miR-497, miR-193, and miR-126 have been identified in different lymphocyte subsets including CD4+ $\mathrm{T}$ cells, CD8+ T cells, B cells, and CD4+ CD25+ Treg cells from patients with MS. Nevertheless, direct involvement and contribution of dysregulated miRNAs in MS has largely remained unknown and needs additional investigation [52]. It is noteworthy that all miRNAs are involved in the pathogenesis of the disease. There are miRNAs that can serve as prognostic markers. For example, the expression of miR$18 \mathrm{~b}$ and miR-599 is related to relapse and miR-96 is involved in remission [53].

Other miRNAs such as miR-124, which is expressed in microglia but not in peripheral monocytes or macrophages, are brain specific. Their function may be to reduce activation of myelin-specific $\mathrm{T}$ cells with a marked suppression of the disease, which would make it a key regulator of microglia quiescence and a good prognostic factor for MS [54].

3.4.4. Type 1 Diabetes. There are few studies related to miRNAs and T1D pathogenesis. But there are some hypotheses that the function of regulatory T cells (Tregs) is influenced by changes in the expression of specific miRNAs (Table 2 ). In Tregs of diabetic patients, there is an increase in the expression of miRNA-510 and decreased expression of both miRNA-342 and miRNA-191. The exact function of these two is not yet known. There are other studies which demonstrate that miRNAs may be the cause of cytokinemediated beta-cell cytotoxicity. This cytotoxicity is achieved when IL-1B and TNF- $\alpha$ induce the expression of miR-21, miR-34a, and miR-146a in pancreatic islets thus producing beta-cell failure by increasing proinflammatory cytokines $[55,56,144]$.

3.4.5. Sjögren's Syndrome (SS). This syndrome is characterized by the inflammation and dysfunction of salivary and lacrimal glands, which cause dry mouth and eyes. Some miRNAs seem to play an important role in SS: miR-5473p, miR-168-3p, miR-150, and miR-149 (Table 2). The first two are overexpressed in salivary glands, while the last two are upregulated in salivary glands and lymphocytes. The exact function of each one of these miRNAs has not yet been elucidated, but their overexpression may be the cause of the downregulation of some mRNAs that are important for correct immune function and for the downregulation of proinflammatory cytokines $[57,109]$.

\section{Conclusions}

Epigenetic research has grown and is now providing new insights into autoimmune diseases. This is possible thanks to advances in technological development, which are enabling epigenomic analysis on a large scale. This improvement in the genetic field has enabled us to find new causes that may explain the etiology of autoimmune diseases and, once again, has shown us that this group of diseases is not caused by a single altered component.

The candidate gene studies have identified a small set of genes that undergo aberrant DNA demethylation and overexpression in SLE and RA, which are the autoimmune diseases that have been the most widely studied in the last few years. This identification of cell-specific targets of epigenetic deregulation in autoimmune rheumatic disorders will provide clinical markers for diagnosis, disease progression, and response to therapies. However, to achieve this, high-throughput approaches are necessary for screening epigenetic alterations in autoimmune diseases related to specific tissue and cell types that are relevant to disease pathogenesis.

Once we have mapped all the altered epigenetic mechanisms that produce each one of the autoimmune diseases, even more research can be done on the therapeutic potential of compounds directed against those epigenetic mechanisms. But to do this, detailed human DNA methylomes, histone modification, and nucleosome positioning maps in healthy and diseased tissues are needed.

\section{References}

[1] C. Dupont, D. R. Armant, and C. A. Brenner, "Epigenetics: definition, mechanisms and clinical perspective," Seminars in Reproductive Medicine, vol. 27, no. 5, pp. 351-357, 2009.

[2] C. T. Wu and J. R. Morris, "Genes, genetics, and epigenetics: a correspondence," Science, vol. 293, no. 5532, pp. 1103-1105, 2001. 
[3] T. Tollefsbol and E. C. Limited, Handbook of Epigenetics: The New Molecular and Medical Genetics, Elsevier Science, Burlington, Canada, 1st edition, 2011.

[4] C. D. Allis, T. Jenuwein, D. Reinberg, and M. L. Caparros, Epigenetics, Cold Spring Harbor, New York, NY, USA, 2007.

[5] E. Ballestar, "Epigenetics lessons from twins: prospects for autoimmune disease," Clinical Reviews in Allergy and Immunology, vol. 39, no. 1, pp. 30-41, 2010.

[6] M. F. Fraga, E. Ballestar, M. F. Paz et al., "Epigenetic differences arise during the lifetime of monozygotic twins," Proceedings of the National Academy of Sciences of the United States of America, vol. 102, no. 30, pp. 10604-10609, 2005.

[7] P. Jarvinen, J. Kaprio, R. Makitalo, M. Koskenvuo, and K. Aho, "Systemic lupus erythematosus and related systemic diseases in a nationwide twin cohort: an increased prevalence of disease in MZ twins and concordance of disease features," Journal of Internal Medicine, vol. 231, no. 1, pp. 67-72, 1992.

[8] D. Deapen, A. Escalante, L. Weinrib et al., "A revised estimate of twin concordance in systemic lupus erythematosus," Arthritis and Rheumatism, vol. 35, no. 3, pp. 311-318, 1992.

[9] K. O. Kyvik, A. Green, and H. Beck-Nielsen, "Concordance rates of insulin dependent diabetes mellitus: a population based study of young Danish twins," British Medical Journal, vol. 311, no. 7010, pp. 913-917, 1995.

[10] J. Kaprio, J. Tuomilehto, M. Koskenvuo et al., "Concordance for Type 1 (insulin-dependent) and Type 2 (non-insulindependent) diabetes mellitus in a population-based cohort of twins in Finland," Diabetologia, vol. 35, no. 11, pp. 1060 1067, 1992.

[11] D. Kumar, N. S. Gemayel, D. Deapen et al., "North-American twins with IDDM: genetic, etiological, and clinical significance of disease concordance according to age, zygosity, and the interval after diagnosis in first twin," Diabetes, vol. 42, no. 9, pp. 1351-1363, 1993.

[12] A. Matsuda and T. Kuzuya, "Diabetic twins in Japan," Diabetes Research and Clinical Practice, vol. 24, pp. S63-S67, 1994.

[13] P. Olmos, R. A'Hern, D. A. Heaton et al., "The significance of the concordance rate for Type 1 (insulin-dependent) diabetes in identical twins," Diabetologia, vol. 31, no. 10, pp. 747-750, 1988.

[14] K. Aho, M. Koskenvuo, J. Tuominen, and J. Kaprio, "Occurrence of rheumatoid arthritis in a nationwide series of twins," Journal of Rheumatology, vol. 13, no. 5, pp. 899-902, 1986.

[15] A. J. Silman, A. J. MacGregor, W. Thomson et al., "Twin concordance rates for rheumatoid arthritis: results from a nationwide study," British Journal of Rheumatology, vol. 32, no. 10, pp. 903-907, 1993.

[16] N. Bellamy, D. Duffy, N. Martin, and J. Mathews, "Rheumatoid arthritis in twins: a study of aetiopathogenesis based on the Australian Twin Registry," Annals of the Rheumatic Diseases, vol. 51, no. 5, pp. 588-593, 1992.

[17] T. H. Brix, K. Christensen, N. V. Holm, B. Harvald, and L. Hegedüs, "A population-based study of graves' disease in danish twins," Clinical Endocrinology, vol. 48, no. 4, pp. 397400, 1998.

[18] E. Kinnunen, J. Juntunen, L. Ketonen et al., "Genetic susceptibility to multiple sclerosis: a co-twin study of a nationwide series," Archives of Neurology, vol. 45, no. 10, pp. 1108-1111, 1988

[19] C. J. Mumford, N. W. Wood, H. Kellar-Wood, J. W. Thorpe, D. H. Miller, and D. A. S. Compston, "The British Isles survey of multiple sclerosis in twins," Neurology, vol. 44, no. 1, pp. 11-15, 1994.
[20] A. D. Sadovnick, H. Armstrong, G. P. A. Rice et al., "A population-based study of multiple sclerosis in twins: update," Annals of Neurology, vol. 33, no. 3, pp. 281-285, 1993.

[21] G. C. Ebers, D. E. Bulman, and A. D. Sadovnick, "A population-based study of multiple sclerosis in twins," The New England Journal of Medicine, vol. 315, no. 26, pp. 1638-1642, 1986.

[22] L. Greco, R. Romino, I. Coto et al., "The first large population based twin study of coeliac disease," Gut, vol. 50, no. 5, pp. 624-628, 2002.

[23] Q. Lu, M. Kaplan, D. Ray et al., "Demethylation of ITGAL (CD11a) regulatory sequences in systemic lupus erythematosus," Arthritis and Rheumatism, vol. 46, no. 5, pp. 1282-1291, 2002.

[24] Q. Lu, A. Wu, L. Tesmer, D. Ray, N. Yousif, and B. Richardson, "Demethylation of $\mathrm{CD}_{40} \mathrm{LG}$ on the inactive $\mathrm{X}$ in T cells from women with lupus," Journal of Immunology, vol. 179, no. 9, pp. 6352-6358, 2007.

[25] M. J. Kaplan, Q. Lu, A. Wu, J. Attwood, and B. Richardson, "Demethylation of promoter regulatory elements contributes to perforin overexpression in $\mathrm{CD}^{+}$lupus T cells," Journal of Immunology, vol. 172, no. 6, pp. 3652-3661, 2004.

[26] K. Oelke, Q. Lu, D. Richardson et al., "Overexpression of $\mathrm{CD}_{70}$ and overstimulation of IgG synthesis by lupus $\mathrm{T}$ cells and T cells treated with DNA methylation inhibitors," Arthritis and Rheumatism, vol. 50, no. 6, pp. 1850-1860, 2004.

[27] B. M. Javierre, A. F. Fernandez, J. Richter et al., "Changes in the pattern of DNA methylation associate with twin discordance in systemic lupus erythematosus," Genome Research, vol. 20, no. 2, pp. 170-179, 2010.

[28] S. Garaud, C. Le Dantec, S. Jousse-Joulin et al., "IL-6 Modulates CD5 expression in B cells from patients with lupus by regulating DNA methylation," Journal of Immunology, vol. 182, no. 9, pp. 5623-5632, 2009.

[29] M. Neidhart, J. Rethage, S. Kuchen et al., "Retrotransposable L1 elements expressed in rheumatoid arthritis synovial tissue: association with genomic DNA hypomethylation and influence on gene expression," Arthritis and Rheumatism, vol. 43, no. 12, pp. 2634-2647, 2000.

[30] C. J. Nile, R. C. Read, M. Akil, G. W. Duff, and A. G. Wilson, "Methylation status of a single CpG site in the IL6 promoter is related to IL6 messenger RNA levels and rheumatoid arthritis," Arthritis and Rheumatism, vol. 58, no. 9, pp. 26862693, 2008.

[31] N. Takami, K. Osawa, Y. Miura et al., "Hypermethylated promoter region of $D R 3$, the death receptor 3 gene, in rheumatoid arthritis synovial cells," Arthritis and Rheumatism, vol. 54, no. 3, pp. 779-787, 2006.

[32] K. L. Schalinske, "Interrelationship between diabetes and homocysteine metabolism: hormonal regulation of cystathionine $\beta$-synthase," Nutrition Reviews, vol. 61, no. 4, pp. 136-138, 2003.

[33] F. G. Mastronardi, A. Noor, D. D. Wood, T. Paton, and M. A. Moscarello, "Peptidyl argininedeiminase $2 \mathrm{CpG}$ island in multiple sclerosis white matter is hypomethylated," Journal of Neuroscience Research, vol. 85, no. 9, pp. 2006-2016, 2007.

[34] M. Kubo, J. Czuwara-Ladykowska, O. Moussa et al., "Persistent down-regulation of Fli1, a suppressor of collagen transcription, in fibrotic scleroderma skin," American Journal of Pathology, vol. 163, no. 2, pp. 571-581, 2003. 
[35] C. C. van Bavel, J. W. Dieker, W. P. Tamboer, J. van der Vlag, and J. H. Berden, "Lupus-derived monoclonal autoantibodies against apoptotic chromatin recognize acetylated conformational epitopes," Molecular Immunology, vol. 48, no. 1-3, pp. 248-256, 2010.

[36] N. Hu, X. Qiu, Y. Luo et al., "Abnormal histone modification patterns in lupus CD4 $4^{+}$T cells," Journal of Rheumatology, vol. 35, no. 5, pp. 804-810, 2008.

[37] D. A. Young, R. L. Lakey, C. J. Pennington et al., "Histone deacetylase inhibitors modulate metalloproteinase gene expression in chondrocytes and block cartilage resorption," Arthritis Research \& Therapy, vol. 7, no. 3, pp. R503-R512, 2005.

[38] K. Nishida, T. Komiyama, S. I. Miyazawa et al., "Histone deacetylase inhibitor suppression of autoantibody-mediated arthritis in mice via regulation of $\mathrm{p} 16^{\mathrm{INK} 4 \mathrm{a}}$ and $\mathrm{p} 21^{\mathrm{WAF} 1 / \mathrm{Cip} 1}$ expression," Arthritis and Rheumatism, vol. 50, no. 10, pp. 3365-3376, 2004.

[39] F. Miao, D. D. Smith, L. Zhang, A. Min, W. Feng, and R. Natarajan, "Lymphocytes from patients with type 1 diabetes display a distinct profile of chromatin histone $\mathrm{H}_{3}$ lysine 9 dimethylation an epigenetic study in diabetes," Diabetes, vol. 57, no. 12, pp. 3189-3198, 2008.

[40] M. E. Cooper and A. El-Osta, "Epigenetics: mechanisms and implications for diabetic complications," Circulation Research, vol. 107, no. 12, pp. 1403-1413, 2010.

[41] X. Pedre, F. Mastronardi, W. Bruck, G. López-Rodas, T. Kuhlmann, and P. Casaccia, "Changed histone acetylation patterns in normal-appearing white matter and early multiple sclerosis lesions," Journal of Neuroscience, vol. 31, no. 9, pp. 3435-3445, 2011.

[42] Y. Tang, X. Luo, H. Cui et al., "MicroRNA-146a contributes to abnormal activation of the type I interferon pathway in human lupus by targeting the key signaling proteins," Arthritis and Rheumatism, vol. 60, no. 4, pp. 1065-1075, 2009.

[43] X. Zhao, Y. Tang, B. Qu et al., "MicroRNA-125a contributes to elevated inflammatory chemokine RANTES levels via targeting KLF13 in systemic lupus erythematosus," Arthritis and Rheumatism, vol. 62, no. 11, pp. 3425-3435, 2010.

[44] W. Pan, S. Zhu, M. Yuan et al., "MicroRNA-21 and microRNA-148a contribute to DNA hypomethylation in lupus $\mathrm{CD}^{+} \mathrm{T}$ cells by directly and indirectly targeting DNA methyltransferase 1," Journal of Immunology, vol. 184, no. 12, pp. 6773-6781, 2010.

[45] K. Calame, "MicroRNA-155 function in B Cells," Immunity, vol. 27, no. 6, pp. 825-827, 2007.

[46] R. M. O’Connell, D. Kahn, W. S.J. Gibson et al., "MicroRNA155 promotes autoimmune inflammation by enhancing inflammatory T cell development," Immunity, vol. 33, no. 4, pp. 607-619, 2010.

[47] J. Stanczyk, D. M. Leslie Pedrioli, F. Brentano et al., "Altered expression of microRNA in synovial fibroblasts and synovial tissue in rheumatoid arthritis," Arthritis and Rheumatism, vol. 58, no. 4, pp. 1001-1009, 2008.

[48] J. Li, Y. Wan, Q. Guo et al., "Altered microRNA expression profile with miR-146a upregulation in $\mathrm{CD}^{+} \mathrm{T}$ cells from patients with rheumatoid arthritis," Arthritis Research \& Therapy, p. R81, 2010.

[49] Y. Nakamachi, S. Kawano, M. Takenokuchi et al., "MicroRNA-124a is a key regulator of proliferation and monocyte chemoattractant protein 1 secretion in fibroblastlike synoviocytes from patients with rheumatoid arthritis,"
Arthritis and Rheumatism, vol. 60, no. 5, pp. 1294-1304, 2009.

[50] C. Du, C. Liu, J. Kang et al., "MicroRNA miR-326 regulates $\mathrm{T}_{\mathrm{H}}-17$ differentiation and is associated with the pathogenesis of multiple sclerosis," Nature Immunology, vol. 10, no. 12, pp. 1252-1259, 2009.

[51] A. Junker, M. Krumbholz, S. Eisele et al., "MicroRNA profiling of multiple sclerosis lesions identifies modulators of the regulatory protein $\mathrm{CD}_{47}$," Brain, vol. 132, no. 12, pp. 33423352, 2009.

[52] G. De Santis, M. Ferracin, A. Biondani et al., "Altered miRNA expression in T regulatory cells in course of multiple sclerosis," Journal of Neuroimmunology, vol. 226, no. 1-2, pp. 165-171, 2010.

[53] D. Otaegui, S. E. Baranzini, R. Armañanzas et al., "Differential micro RNA expression in PBMC from multiple sclerosis patients," PLoS ONE, vol. 4, no. 7, article e6309, 2009.

[54] E. D. Ponomarev, T. Veremeyko, N. Barteneva, A. M. Krichevsky, and H. L. Weiner, "MicroRNA-124 promotes microglia quiescence and suppresses EAE by deactivating macrophages via the C/EBP- $\alpha$-PU.1 pathway," Nature Medicine, vol. 17, no. 1, pp. 64-70, 2011.

[55] R. Hezova, O. Slaby, P. Faltejskova et al., "microRNA342, microRNA-191 and microRNA-510 are differentially expressed in T regulatory cells of type 1 diabetic patients," Cellular Immunology, vol. 260, no. 2, pp. 70-74, 2010.

[56] E. Roggli, A. Britan, S. Gattesco et al., "Involvement of microRNAs in the cytotoxic effects exerted by proinflammatory cytokines on pancreatic $\beta$-cells," Diabetes, vol. 59, no. 4, pp. 978-986, 2010.

[57] I. Alevizos and G. G. Illei, "MicroRNAs in Sjögren's syndrome as a prototypic autoimmune disease," Autoimmunity Reviews, vol. 9, no. 9, pp. 618-621, 2010.

[58] C. A. Cooney, A. A. Dave, and G. L. Wolff, "Maternal methyl supplements in mice affect epigenetic variation and DNA methylation of offspring," Journal of Nutrition, vol. 132, supplement 8, pp. 2393S-2400S, 2002.

[59] B. T. Heijmans, E. W. Tobi, A. D. Stein et al., "Persistent epigenetic differences associated with prenatal exposure to famine in humans," Proceedings of the National Academy of Sciences of the United States of America, vol. 105, no. 44, pp. 17046-17049, 2008.

[60] L. H. Lumey, A. D. Stein, H. S. Kahn et al., "Cohort profile: The Dutch Hunger Winter Families Study," International Journal of Epidemiology, vol. 36, no. 6, pp. 1196-1204, 2007.

[61] L. H. Lumey, A. D. Stein, H. S. Kahn, and J. A. Romijn, "Lipid profiles in middle-aged men and women after famine exposure during gestation: The Dutch Hunger Winter Families Study," American Journal of Clinical Nutrition, vol. 89, no. 6, pp. 1737-1743, 2009.

[62] T. J. Roseboom, J. H. P. Van der Meulen, C. Osmond, D. J. P. Barker, A. C. J. Ravelli, and O. P. Bleker, "Plasma lipid profiles in adults after prenatal exposure to the Dutch famine," American Journal of Clinical Nutrition, vol. 72, no. 5, pp. 1101-1106, 2000.

[63] A. D. Stein, H. S. Kahn, A. Rundle, P. A. Zybert, K. Van Der Pal-De Bruin, and L. H. Lumey, "Anthropometric measures in middle age after exposure to famine during gestation: evidence from the Dutch famine," American Journal of Clinical Nutrition, vol. 85, no. 3, pp. 869-876, 2007.

[64] A. C. J. Ravelli, J. H. P. Van Der Meulen, C. Osmond, D. J. P. Barker, and O. P. Bleker, "Obesity at the age of $50 \mathrm{y}$ in men and women exposed to famine prenatally," American Journal of Clinical Nutrition, vol. 70, no. 5, pp. 811-816, 1999. 
[65] R. C. Painter, S. R. De Rooij, P. M. Bossuyt et al., "Early onset of coronary artery disease after prenatal exposure to the Dutch famine," American Journal of Clinical Nutrition, vol. 84, no. 2, pp. 322-327, 2006.

[66] E. Susser, R. Neugebauer, H. W. Hoek et al., "Schizophrenia after prenatal famine further evidence," Archives of General Psychiatry, vol. 53, no. 1, pp. 25-31, 1996.

[67] H. W. Hoek, A. S. Brown, and E. Susser, "The Dutch Famine and schizophrenia spectrum disorders," Social Psychiatry and Psychiatric Epidemiology, vol. 33, no. 8, pp. 373-379, 1998.

[68] A. S. Brown, J. Van Os, C. Driessens, H. W. Hoek, and E. S. Susser, "Further evidence of relation between prenatal famine and major affective disorder," American Journal of Psychiatry, vol. 157, no. 2, pp. 190-195, 2000.

[69] K. M. Niles, D. Chan, S. la Salle, C. C. Oakes, and J. M. Trasler, "Critical period of nonpromoter DNA methylation acquisition during prenatal male germ cell development," PLoS ONE, vol. 6, no. 9, article e24156, 2011.

[70] P. Liang, F. Song, S. Ghosh et al., "Genome-wide survey reveals dynamic widespread tissue-specific changes in DNA methylation during development," BMC Genomics, vol. 12, article 231, 2011.

[71] D. A. Khavari, G. L. Sen, and J. L. Rinn, "DNA methylation and epigenetic control of cellular differentiation," Cell Cycle, vol. 9, no. 19, pp. 3880-3883, 2010.

[72] Z. X. Chen, J. R. Mann, C. L. Hsieh, A. D. Riggs, and F. Chédin, "Physical and functional interactions between the human DNMT3L protein and members of the de novo methyltransferase family," Journal of Cellular Biochemistry, vol. 95, no. 5, pp. 902-917, 2005.

[73] S. K. T. Ooi and T. H. Bestor, "The colorful history of active DNA demethylation,” Cell, vol. 133, no. 7, pp. 1145-1148, 2008.

[74] E. L. Fritz and F. N. Papavasiliou, "Cytidine deaminases: AIDing DNA demethylation?" Genes and Development, vol. 24, no. 19, pp. 2107-2114, 2010.

[75] S. Fan and X. Zhang, "CpG island methylation pattern in different human tissues and its correlation with gene expression," Biochemical and Biophysical Research Communications, vol. 383, no. 4, pp. 421-425, 2009.

[76] A. Bird, "DNA methylation patterns and epigenetic memory," Genes and Development, vol. 16, no. 1, pp. 6-21, 2002.

[77] A. P. Feinberg, "Genome-scale approaches to the epigenetics of common human disease," Virchows Archiv, vol. 456, no. 1, pp. 13-21, 2010.

[78] M. P. Ball, J. B. Li, Y. Gao et al., "Targeted and genome-scale strategies reveal gene-body methylation signatures in human cells," Nature Biotechnology, vol. 27, no. 4, pp. 361-368, 2009.

[79] A. Portela and M. Esteller, "Epigenetic modifications and human disease," Nature Biotechnology, vol. 28, no. 10, pp. 1057-1068, 2010.

[80] T. Kouzarides, "Chromatin modifications and their function," Cell, vol. 128, no. 4, pp. 693-705, 2007.

[81] D. Huertas, R. Sendra, and P. Muñoz, "Chromatin dynamics coupled to DNA repair," Epigenetics, vol. 4, no. 1, pp. 31-42, 2009.

[82] A. J. M. De Ruijter, A. H. Van Gennip, H. N. Caron, S. Kemp, and A. B. P. Van Kuilenburg, "Histone deacetylases (HDACs): characterization of the classical HDAC family," Biochemical Journal, vol. 370, no. 3, pp. 737-749, 2003.

[83] S. Y. Roth, J. M. Denu, and C. D. Allis, "Histone acetyltransferases," The Annual Review of Biochemistry, vol. 70, pp. 81120, 2001.
[84] P. D. Gregory, K. Wagner, and W. Horz, "Histone acetylation and chromatin remodeling," Experimental Cell Research, pp. 195-202, 2001.

[85] Z. Wang, C. Zang, J. A. Rosenfeld et al., "Combinatorial patterns of histone acetylations and methylations in the human genome," Nature Genetics, vol. 40, no. 7, pp. 897-903, 2008.

[86] Q. Duan, H. Chen, M. Costa, and W. Dai, "Phosphorylation of $\mathrm{H}_{3} \mathrm{~S}_{10}$ blocks the access of $\mathrm{H}_{3} \mathrm{~K}_{9}$ by specific antibodies and histone methyltransferase: implication in regulating chromatin dynamics and epigenetic inheritance during mitosis," Journal of Biological Chemistry, vol. 283, no. 48, pp. 3358533590, 2008.

[87] D. E. Schones, K. Cui, S. Cuddapah et al., "Dynamic regulation of nucleosome positioning in the human genome," Cell, vol. 132, no. 5, pp. 887-898, 2008.

[88] R. K. Chodavarapu, S. Feng, Y. V. Bernatavichute et al., "Relationship between nucleosome positioning and DNA methylation," Nature, vol. 466, no. 7304, pp. 388-392, 2010.

[89] D. P. Bartel, "MicroRNAs: genomics, biogenesis, mechanism, and function," Cell, vol. 116, no. 2, pp. 281-297, 2004.

[90] V. Scaria, M. Hariharan, S. Maiti, B. Pillai, and S. K. Brahmachari, "Host-virus interaction: a new role for microRNAs," Retrovirology, vol. 3, article no. 68, 2006.

[91] J. M. Anaya, L. Gómez, and J. Castiblanco, "Is there a common genetic basis for autoimmune diseases?" Clinical and Developmental Immunology, vol. 13, no. 2-4, pp. 185195, 2006.

[92] J. M. Anaya, “The autoimmune tautology," Arthritis Research \& Therapy, vol. 12, article 147, 2010.

[93] W. Lei, Y. Luo, K. Yan et al., "Abnormal DNA methylation in $\mathrm{CD} 4^{+} \mathrm{T}$ cells from patients with systemic lupus erythematosus, systemic sclerosis, and dermatomyositis," Scandinavian Journal of Rheumatology, vol. 38, no. 5, pp. 369-374, 2009.

[94] Q. Lu, A. Wu, D. Ray et al., "DNA methylation and chromatin structure regulate T cell perforin gene expression," Journal of Immunology, vol. 170, no. 10, pp. 5124-5132, 2003.

[95] Q. Lu, D. Ray, D. Gutsch, and B. Richardson, "Effect of DNA methylation and chromatin structure on ITGAL expression," Blood, vol. 99, no. 12, pp. 4503-4508, 2002.

[96] Y. Zhou and Q. Lu, "DNA methylation in T cells from idiopathic lupus and drug-induced lupus patients," Autoimmunity Reviews, vol. 7, no. 5, pp. 376-383, 2008.

[97] B. H. Lee, S. Yegnasubramanian, X. Lin, and W. G. Nelson, "Procainamide is a specific inhibitor of DNA methyltransferase 1," Journal of Biological Chemistry, vol. 280, no. 49, pp. 40749-40756, 2005.

[98] C. Deng, Q. Lu, Z. Zhang et al., "Hydralazine may induce autoimmunity by inhibiting extracellular signal—regulated kinase pathway signaling," Arthritis and Rheumatism, vol. 48, no. 3, pp. 746-756, 2003.

[99] G. Gorelik, Y. F. Jing, A. Wu, A. H. Sawalha, and B. Richardson, "Impaired $\mathrm{T}$ cell protein kinase $\mathrm{C} \delta$ activation decreases ERK pathway signaling in idiopathic and hydralazine-induced lupus," Journal of Immunology, vol. 179, no. 8, pp. 5553-5563, 2007.

[100] J. Quddus, K. J. Johnson, J. Gavalchin et al., "Treating activated $\mathrm{CD}^{+} \mathrm{T}$ cells with either of two distinct DNA methyltransferase inhibitors, 5-azacytidine or procainamide, is sufficient to cause a lupus-like disease in syngeneic mice," Journal of Clinical Investigation, vol. 92, no. 1, pp. 38-53, 1993.

[101] R. L. Yung, J. Quddus, C. E. Chrisp, K. J. Johnson, and B. C. Richardson, "Mechanisms of drug-induced lupus: I. Cloned 
Th2 cells modified with DNA methylation inhibitors in vitro cause autoimmunity in vivo," Journal of Immunology, vol. 154, no. 6, pp. 3025-3035, 1995.

[102] E. Cornacchia, J. Golbus, J. Maybaum, J. Strahler, S. Hanash, and B. Richardson, "Hydralazine and procainamide inhibit T cell DNA methylation and induce autoreactivity," Journal of Immunology, vol. 140, no. 7, pp. 2197-2200, 1988.

[103] E. Karouzakis, R. E. Gay, B. A. Michel, S. Gay, and M. Neidhart, "DNA hypomethylation in rheumatoid arthritis synovial fibroblasts," Arthritis and Rheumatism, vol. 60, no. 12, pp. 3613-3622, 2009.

[104] L. -H. Fu, C. -L. Ma, B. Cong, S. -J. Li, H. -Y. Chen, and J. -G. Zhang, "Hypomethylation of proximal CpG motif of interleukin-10 promoter regulates its expression in human rheumatoid arthritis," Acta Pharmacologica Sinica, vol. 32, no. 11, pp. 1373-1380, 2011.

[105] Y. I. Kim, J. W. Logan, J. B. Mason, and R. Roubenoff, "DNA hypomethylation in inflammatory arthritis: reversal with methotrexate," Journal of Laboratory and Clinical Medicine, vol. 128, no. 2, pp. 165-172, 1996.

[106] S. Kuchen, C. A. Seemayer, J. Rethage et al., "The L1 retroelement-related $\mathrm{p} 40$ protein induces $\mathrm{p} 38 \delta$ MAP kinase," Autoimmunity, vol. 37, no. 1, pp. 57-65, 2004.

[107] M. J. Bull, A. S. Williams, Z. Mecklenburgh et al., “The death receptor 3-TNF-like protein 1A pathway drives adverse bone pathology in inflammatory arthritis," Journal of Experimental Medicine, vol. 205, no. 11, pp. 2457-2464, 2008.

[108] K. Osawa, N. Takami, K. Shiozawa, A. Hashiramoto, and S. Shiozawa, "Death receptor $3(D R 3)$ gene duplication in a chromosome region 1p36.3: gene duplication is more prevalent in rheumatoid arthritis," Genes and Immunity, vol. 5, no. 6, pp. 439-443, 2004.

[109] F. Meda, M. Folci, A. Baccarelli, and C. Selmi, "The epigenetics of autoimmunity," Cellular \& Molecular Immunology, vol. 8, no. 3, pp. 226-236, 2011.

[110] M. F. McCarty, "Insulin secretion as a potential determinant of homocysteine levels," Medical Hypotheses, vol. 55, no. 5, pp. 454-455, 2000.

[111] E. P. Wijekoon, M. E. Brosnan, and J. T. Brosnan, "Homocysteine metabolism in diabetes," Biochemical Society Transactions, vol. 35, no. 5, pp. 1175-1179, 2007.

[112] E. Arany, B. Strutt, P. Romanus, C. Remacle, B. Reusens, and D. J. Hill, "Taurine supplement in early life altered islet morphology, decreased insulitis and delayed the onset of diabetes in non-obese diabetic mice," Diabetologia, vol. 47, no. 10, pp. 1831-1837, 2004.

[113] S. Boujendar, E. Arany, D. Hill, C. Remacle, and B. Reusens, "Taurine supplementation of a low protein diet fed to rat dams normalizes the vascularization of the fetal endocrine pancreas," Journal of Nutrition, vol. 133, no. 9, pp. 28202825, 2003.

[114] M. A. Moscarello, F. G. Mastronardi, and D. D. Wood, "The role of citrullinated proteins suggests a novel mechanism in the pathogenesis of multiple sclerosis," Neurochemical Research, vol. 32, no. 2, pp. 251-256, 2007.

[115] A. A. Musse, J. M. Boggs, and G. Harauz, "Deimination of membrane-bound myelin basic protein in multiple sclerosis exposes an immunodominant epitope," Proceedings of the National Academy of Sciences of the United States of America, vol. 103, no. 12, pp. 4422-4427, 2006.

[116] L. R. Tranquill, L. Cao, N. C. Ling, H. Kalbacher, R. M. Martin, and J. N. Whitaker, "Enhanced T cell responsiveness to citrulline-containing myelin basic protein in multiple sclerosis patients," Multiple Sclerosis, vol. 6, no. 4, pp. 220225, 2000.

[117] R. Calabrese, M. Zampieri, R. Mechelli et al., "Methylationdependent PAD2 upregulation in multiple sclerosis peripheral blood," Multiple Sclerosis. In press.

[118] Y. Wang, P. S. Fan, and B. Kahaleh, "Association between enhanced type I collagen expression and epigenetic repression of the FLI1 gene in scleroderma fibroblasts," Arthritis and Rheumatism, vol. 54, no. 7, pp. 2271-2279, 2006.

[119] G. Schett, J. Smolen, C. Zimmermann et al., "The autoimmune response to chromatin antigens in systemic lupus erythematosus: autoantibodies against histone $\mathrm{H} 1$ are a highly specific marker for SLE associated with increased disease activity," Lupus, vol. 11, no. 11, pp. 704-715, 2002.

[120] A. Bruns, S. Bläss, G. Hausdorf, G. R. Burmester, and F. Hiepe, "Nucleosomes are major T and B cell autoantigens in systemic lupus erythematosus," Arthritis and Rheumatism, vol. 43, no. 10, pp. 2307-2315, 2000.

[121] S. Koutouzov, A. L. Jeronimo, H. Campos, and Z. Amoura, "Nucleosomes in the pathogenesis of systemic lupus erythematosus," Rheumatic Disease Clinics of North America, vol. 30, no. 3, pp. 529-558, 2004.

[122] Z. Amoura, S. Koutouzov, and J. C. Piette, "The role of nucleosomes in lupus," Current Opinion in Rheumatology, vol. 12, no. 5, pp. 369-373, 2000.

[123] C. C. Van Bavel, J. W. Dieker, Y. Kroeze et al., "Apoptosisinduced histone $\mathrm{H} 3$ methylation is targeted by autoantibodies in systemic lupus erythematosus," Annals of the Rheumatic Diseases, vol. 70, no. 1, pp. 201-207, 2011.

[124] Z. Zhang, L. Song, K. Maurer, M. A. Petri, and K. E. Sullivan, "Global H4 acetylation analysis by ChIP-chip in systemic lupus erythematosus monocytes," Genes and Immunity, vol. 11, no. 2, pp. 124-133, 2010.

[125] Y. Dai, L. Zhang, C. Hu, and Y. Zhang, "Genome-wide analysis of histone $\mathrm{H} 3$ lysine 4 trimethylation by ChIPchip in peripheral blood mononuclear cells of systemic lupus erythematosus patients," Clinical and Experimental Rheumatology, vol. 28, no. 2, pp. 158-168, 2010.

[126] Z. Zhang, L. Song, K. Maurer, A. Bagashev, and K. E. Sullivan, "Monocyte polarization: the relationship of genome-wide changes in $\mathrm{H} 4$ acetylation with polarization," Genes and Immunity, vol. 12, no. 6, pp. 445-456, 2011.

[127] J. Buckland, "Rheumatoid arthritis: HDAC and HDACi: pathogenetic and mechanistic insights," Nature Reviews Rheumatology, vol. 7, no. 12, p. 682, 2011.

[128] A. M. Grabiec and K. A. Reedquist, "Histone deacetylases in rheumatoid arthritis: epigenetics and epiphenomena," Arthritis Research \& Therapy, vol. 12, article 142, 2010.

[129] L. C. Huber, M. Brock, H. Hemmatazad et al., "Histone deacetylase/acetylase activity in total synovial tissue derived from rheumatoid arthritis and osteoarthritis patients," Arthritis and Rheumatism, vol. 56, no. 4, pp. 1087-1093, 2007.

[130] H. Manabe, Y. Nasu, T. Komiyama et al., "Inhibition of histone deacetylase down-regulates the expression of hypoxiainduced vascular endothelial growth factor by rheumatoid synovial fibroblasts," Inflammation Research, vol. 57, no. 1, pp. 4-10, 2008.

[131] A. M. Grabiec, O. Korchynskyi, P. P. Tak, and K. A. Reedquist, "Histone deacetylase inhibitors suppress rheumatoid arthritis fibroblast-like synoviocyte and macrophage IL6 production by accelerating mRNA decay," Annals of the Rheumatic Diseases, vol. 71, no. 3, pp. 424-431, 2012. 
[132] Q. Y. Choo, P. C. Ho, Y. Tanaka, and H. S. Lin, "Histone deacetylase inhibitors MS-275 and SAHA induced growth arrest and suppressed lipopolysaccharide-stimulated NFkappaB p65 nuclear accumulation in human rheumatoid arthritis synovial fibroblastic E11 cells," Rheumatology, pp. 1447-1460, 2010.

[133] Y. Nasu, K. Nishida, S. Miyazawa et al., "Trichostatin A, a histone deacetylase inhibitor, suppresses synovial inflammation and subsequent cartilage destruction in a collagen antibodyinduced arthritis mouse model," Osteoarthritis and Cartilage, vol. 16, no. 6, pp. 723-732, 2008.

[134] L. M. Villeneuve, M. A. Reddy, L. L. Lanting, M. Wang, L. Meng, and R. Natarajan, "Epigenetic histone $\mathrm{H}_{3}$ lysine 9 methylation in metabolic memory and inflammatory phenotype of vascular smooth muscle cells in diabetes," Proceedings of the National Academy of Sciences of the United States of America, vol. 105, no. 26, pp. 9047-9052, 2008.

[135] Y. Li, M. A. Reddy, F. Miao et al., "Role of the histone $\mathrm{H}_{3}$ lysine 4 methyltransferase, $\mathrm{SET}_{7 / 9}$, in the regulation of NF-kappaB-dependent inflammatory genes. Relevance to diabetes and inflammation," The Journal of Biological Chemistry, vol. 283, no. 39, pp. 26771-26781, 2008.

[136] L. M. Villeneuve and R. Natarajan, "The role of epigenetics in the pathology of diabetic complications," American Journal of Physiology, vol. 299, no. 1, pp. F14-F25, 2010.

[137] M. A. Reddy and R. Natarajan, "Epigenetic mechanisms in diabetic vascular complications," Cardiovascular Research, vol. 90, no. 3, pp. 421-429, 2011.

[138] D. J. Verlaan, S. Berlivet, G. M. Hunninghake et al., "Allele-specific chromatin remodeling in the $\mathrm{ZPBP}_{2} /$ $\mathrm{GSDMB}_{\mathrm{ORMDL}}$ locus associated with the risk of asthma and autoimmune disease," American Journal of Human Genetics, vol. 85, no. 3, pp. 377-393, 2009.

[139] S. Zhao, Y. Wang, Y. Liang et al., "MicroRNA-126 regulates DNA methylation in $\mathrm{CD}^{+} \mathrm{T}$ cells and contributes to systemic lupus erythematosus by targeting DNA methyltransferase 1," Arthritis and Rheumatism, vol. 63, no. 5, pp. 1376-1386, 2011.

[140] T. Nakasa, S. Miyaki, A. Okubo et al., "Expression of MicroRNA-146 in rheumatoid arthritis synovial tissue," Arthritis and Rheumatism, vol. 58, no. 5, pp. 1284-1292, 2008.

[141] T. Niimoto, T. Nakasa, M. Ishikawa et al., "MicroRNA-146a expresses in interleukin-17 producing $\mathrm{T}$ cells in rheumatoid arthritis patients," BMC Musculoskeletal Disorders, vol. 11, article 209, 2010.

[142] J. Stanczyk, C. Ospelt, E. Karouzakis et al., "Altered expression of microRNA-203 in rheumatoid arthritis synovial fibroblasts and its role in fibroblast activation," Arthritis and Rheumatism, vol. 63, no. 2, pp. 373-381, 2011.

[143] S. Kawano and Y. Nakamachi, "MiR-124a as a key regulator of proliferation and MCP-1 secretion in synoviocytes from patients with rheumatoid arthritis," Annals of the Rheumatic Diseases, vol. 70, supplement 1, pp. i88-i91, 2011.

[144] Q. -S. Mi, H. -Z. He, Z. Dong, C. Isales, and L. Zhou, "MicroRNA deficiency in pancreatic islet cells exacerbates streptozotocin-induced murine autoimmune diabetes," Cell Cycle, vol. 9, no. 15, pp. 3127-3129, 2010. 


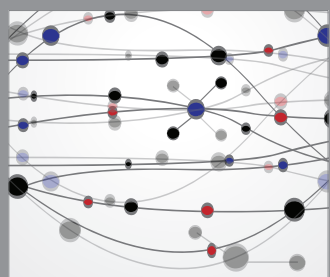

The Scientific World Journal
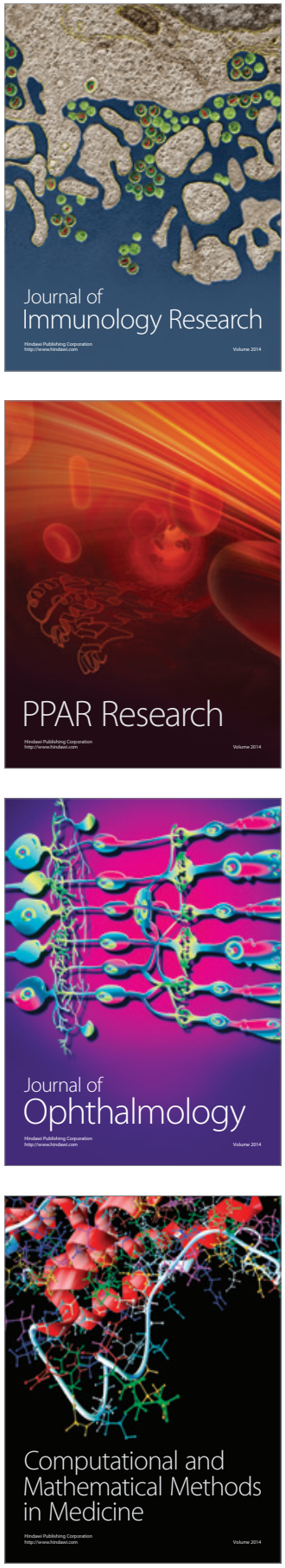

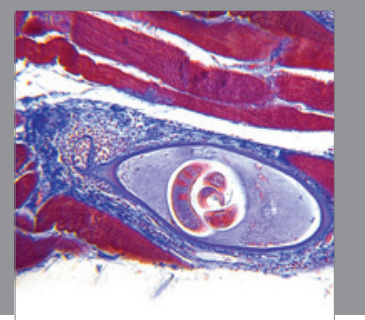

Gastroenterology

Research and Practice
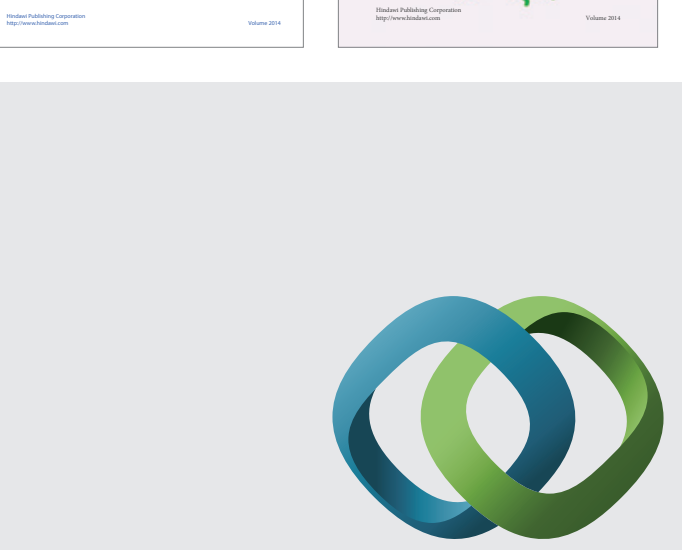

\section{Hindawi}

Submit your manuscripts at

http://www.hindawi.com
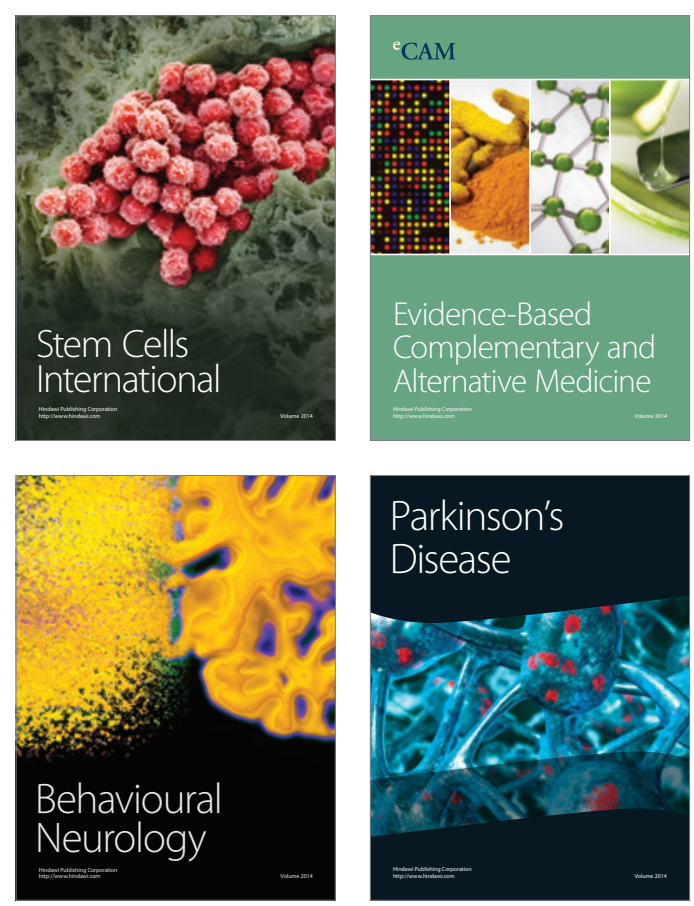

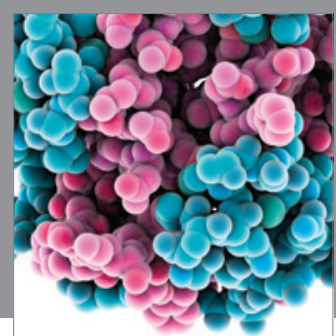

Journal of
Diabetes Research

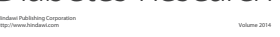

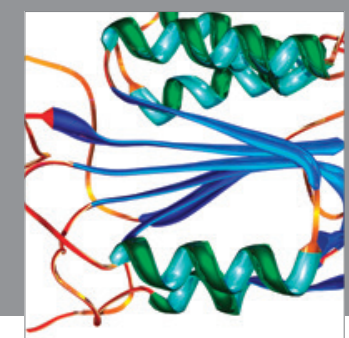

Disease Markers
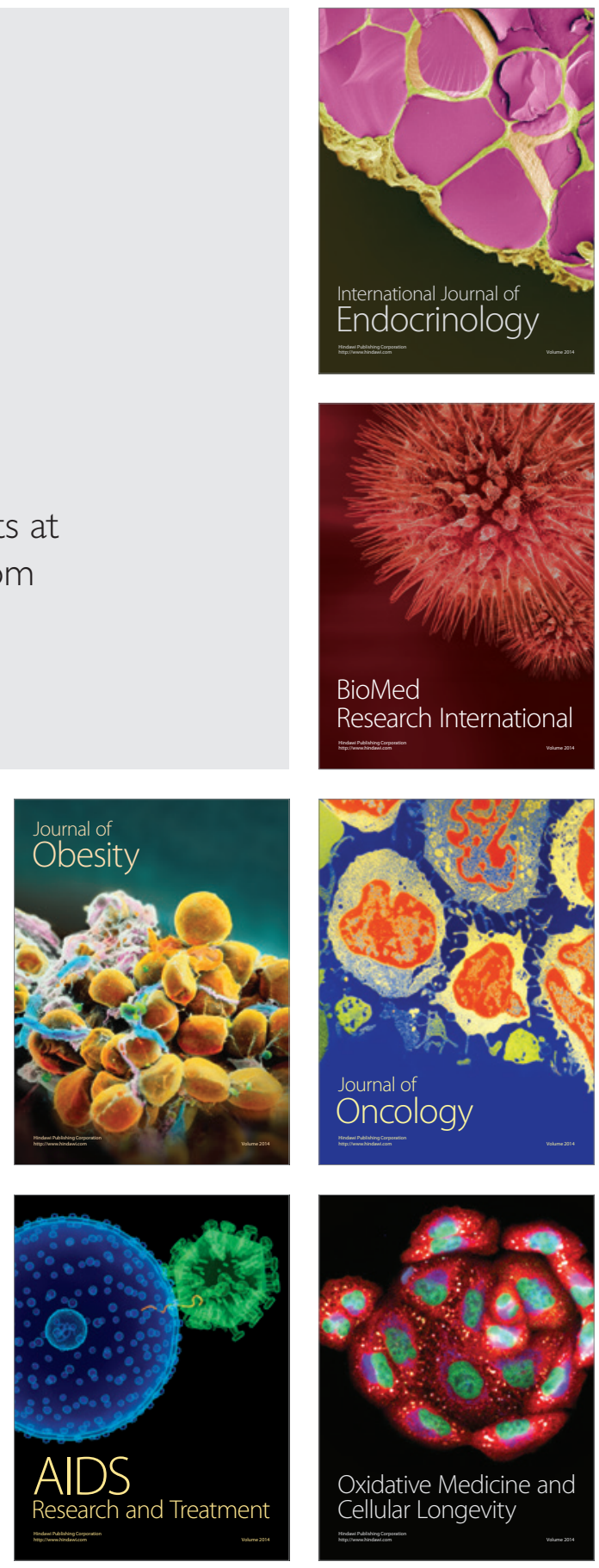